ISSN: 0212-0267

DOI: http://dx.doi.org/IO.I420I/hedu20I635237269

\title{
ALBERTO BONET Y SU ESTUDIO SOBRE LA CONCIENCIA MORAL DEL NIÑO (1927): A PROPÓSITO DE LOS PRIMEROS TRABAJOS SOBRE LA EDUCACIÓN MORAL EN LA UNIVERSIDAD DE BARCELONA
}

\section{Alberto Bonet and his study on the moral conscience of the child (1927): A propos of the first works on moral education at the University of Barcelona}

\author{
Monserrat PAYÁ SÁNCHEZ \\ Universidad de Barcelona \\ Correo-e:mpaya@ub.edu \\ Conrad Vilanou Torrano \\ Universidad de Barcelona \\ Correo-e: cvilanou@ub.edu
}

Recepción: Io de abril de 20I4. Envío a informantes: 29 de mayo de 2014.

Fecha de aceptación definitiva: ro de enero de 2015

Resumen: En este trabajo los autores presentan un análisis histórico de la tradición filosófica catalana (Ramón Martí de Eixalá, Francisco J. Llorens Barba, Tomás Carreras Artau, etc.) que se caracteriza por una filosofía de la conciencia, de innegables consecuencias educativas. Si en Madrid triunfó el krausismo, en Cataluña se aclimató la escuela del sentido común que destaca la conciencia tanto en el orden del conocimiento como en la praxis moral. La llegada de Tomás Carreras Artau a la cátedra de Ética de la Universidad de Barcelona en I9I2 propició la aparición de un Seminario, entre cuyos trabajos descuella el libro de Alberto Bonet -futuro dirigente de la Acción Católica Española- sobre la conciencia moral del niño (1927). A pesar de que este Seminario de Ética quedó un tanto arrinconado por el Seminario de Pedagogía que abrió Joaquín Xirau en 1930, lo cierto es que el magisterio de Alejandro Sanvisens -el discípulo predilecto de Tomás Carreras Artau- permitió 
ALBERTO BONET Y SU ESTUDIO SOBRE LA CONCIENCIA MORAL DEL NIÑO (I927): A PROPÓSITO DE LOS PRIMEROS TRABAJOS SOBRE LA EDUCACIÓN MORAL ... MONSERRAT PAYÁ SÁNCHEZ Y CONRAD VILANOU TORRANO

la configuración de una pedagogía de la conciencia que se encuentra en la base de los estudios sobre educación moral generados en la Universidad de Barcelona, al abrigo del GREM (Grup de Recerca en Educació Moral), fundado en 1988.

Palabras clave: historia de la filosofía; pensamiento pedagógico; ética; conciencia; conciencia moral del niño; Francisco J. Llorens Barba; Tomás Carreras Artau; Alberto Bonet; Alejandro Sanvisens; pedagogía de la conciencia; educación moral.

AвSTRACT: In this work the authors present a historical analysis of the Catalan philosophical tradition (Ramón Martí de Eixalá, Francisco J. Llorens Barba, Tomás Carreras Artau et al.) characterised by a philosophy of the conscience and its undeniable educational consequences. If Krausism was triumphing in Madrid, in Catalonia the school of common sense was taking hold, distinguished by conscience both in the order of knowledge and in moral praxis. When Tomás Carreras Artau took over the chair of Ethics at the University of Barcelona in 1912, a Seminar began that featured the work by Albert Bonet (the future leader of Spain's Catholic Action) on the moral conscience of the child (1927) as one of its most outstanding contributions. Although to a certain extent the Ethics Seminar was later discarded in favour of the Pedagogy Seminar which Joaquín Xirau began in 1930, it is true that the teachings of Alejandro Sanvisens (Tomás Carreras Artau's prize pupil) permitted the configuration of a pedagogy of the conscience which is found in the roots of studies on moral education generated at the University of Barcelona by the GREM (Moral Education Research Group), founded in 1988.

KEY WORDs: history of philosophy; pedagogic thought; ethics; conscience; moral conscience of the child; Francisco J. Xavier Llorens Barba; Tomás Carreras Artau; Alberto Bonet; Alejandro Sanvisens; pedagogy of the conscience; moral education.

En recuerdo del profesor Alejandro Sanvisens Marfull (I9I8I995), en el vigésimo aniversario de su fallecimiento

$\mathrm{E}$

S SABIDO QUE EL DÍA 5 DE DICIEMBRE DE 1930 comenzó a caminar el Seminario de Pedagogía de la Universidad de Barcelona, bajo la dirección del profesor Joaquín Xirau. Discípulo de M. B. Cossío, Xirau se especializó en el campo de la Filosofía de la Educación, publicando en el exilio su obra más emblemática Amor y mundo (1940), donde defendía la viabilidad pedagógica de la charitas cristiana frente al eros helénico. En el programa del Seminario del curso I930-I93I se anunciaban los distintos trabajos de laboratorio, cursos monográficos y conferencias públicas dejando, bien a las claras, cuáles eran sus objetivos: contribuir al perfeccionamiento profesional y espiritual de los maestros. Se perseguía, pues, atraer a los maestros a la Universidad y acercar la Universidad 
ALBERTO BONET Y SU ESTUDIO SOBRE LA CONCIENCIA MORAL DEL NIÑO (I927): A PROPÓSITO DE LOS PRIMEROS TRABAJOS SOBRE LA EDUCACIÓN MORAL ... MONSERRAT PAYÁ SÁNCHEZ Y CONRAD VILANOU TORRANO

a la escuela con la intención de que ambas instituciones -escuela y universidadpalpitasen al unísono, a fin de mejorar la formación de los profesionales de la enseñanza confiriéndoles una esfera ideal de valores.

Ahora bien, este proceso de institucionalización universitaria de la Pedagogía no estuvo exento de controversias y disputas desde el momento que existía un Seminario de Ética que dirigía el profesor Tomás Carreras y Artau desde i913. De hecho, la llegada de Xirau a Barcelona, en 1928, despertó más de una rivalidad no sólo intelectual y profesional, sino también personal y política. Mientras Tomás Carreras Artau militó en la derecha (Liga Regionalista) y tuvo que refugiarse en el extranjero durante la Guerra Civil, Joaquín Xirau había sido uno de los fundadores de la Unión Socialista de Cataluña, marchando al exilio en enero de 1939 junto al poeta Antonio Machado. Como bien se puede deducir, estos dos nombres -Tomás Carreras Artau y Joaquín Xirau- ejemplarizan la dramática lucha de ideas que significó la Guerra Civil, situándose respectivamente en cada uno de los bandos contendientes.

En realidad, las tensiones entre ambos se vislumbran en la correspondencia que Xirau sostuvo con M. B. Cossío, cuando solicitaba su ayuda a fin de que el Gobierno de la Segunda República diese su apoyo a la implantación de los estudios de la licenciatura de Pedagogía en la Universidad de Barcelona, que ya habían sido concedidos a Madrid. Además, Tomás Carreras Artau censuró, desde su escaño en el Parlamento de Cataluña, la política cultural de la Generalidad de Cataluña que seguía a pies juntillas las indicaciones de Joaquín Xirau, omnipresente en aquella época. Por otra parte, vale la pena significar que Carreras Artau confiaba en la existencia de una tradición filosófica catalana que se remontaba a Llorens Barba -el maestro barcelonés de Menéndez Pelayo- ${ }^{2}$ que destacaba la importancia de la conciencia, aspecto que -a nuestro entender- resulta fundamental para entender el arraigo y desarrollo de los estudios sobre educación moral que han tenido como núcleo la Universidad de Barcelona. No en balde, el Seminario de Ética-que quedó relegado a un lugar secundario en virtud del protagonismo del Seminario de Pedagogía, puesto en marcha por Xirau- desarrolló diversos trabajos de cátedra, entre los que destaca el estudio de Alberto Bonet-que fuera dirigente de la Acción Católica Española después de 1939- titulado La conciencia

\footnotetext{
Llopart, Pilar: «De Joaquim Xirau a M. B. Cossío: dotze cartes i una targeta de visita», Temps d'Educació, núm. 27 (2002-2003), pp. 419-439.

2 Diversos autores han destacado la influencia de Llorens en la formación intelectual de Marcelino Menéndez Pelayo, cuyas Historia de las ideas estéticas era muy familiar al profesor Sanvisens. Miguel Artigas, en su biografía La vida y la obra de Menéndez Pelayo, escribe lo siguiente: «Llorens era un profesor socrático, no escribía apenas, hablaba, preguntaba y hacía discurrir a los alumnos, exaltaba el testimonio de la conciencia y el valor del análisis subjetivo» (Zaragoza, Heraldo de Aragón, 1939, p. 36). Se puede añadir que Artigas -director de la Biblioteca Nacional- promovió la publicación del libro Una poderosa fuerza secreta: La Institución Libre de Enseñanza (San Sebastián, I940) en que denigra la influencia de los discípulos de Giner de los Ríos. Se dibujan, pues, dos Españas: la liberal-progresista, de Sanz del Río y el krausismo, con Cossío, Xirau y Serra Húnter; y la liberal-conservadora, de Balmes, Menéndez Pelayo y, lógicamente, Francisco Llorens Barba y Tomás Carreras Artau.
} 
ALBERTO BONET Y SU ESTUDIO SOBRE LA CONCIENCIA MORAL DEL NIÑO (I927): A PROPÓSITO DE LOS PRIMEROS TRABAJOS SOBRE LA EDUCACIÓN MORAL ... MONSERRAT PAYÁ SÁNCHEZ Y CONRAD VILANOU TORRANO

moral del niño, que data de 1927 y que, por su importancia, merece una atención especial y central en este artículo3.

\section{La conciencia, un rasgo de la filosofía catalana}

Todo indica que con relación al tema de la conciencia, Tomás Carreras Artau y Alejandro Sanvisens -su más preclaro discípulo- pueden ser considerados miembros de la escuela filosófica catalana y, muy especialmente, del eje formado por Ramón Martí de Eixalá (I808-I857) y Francisco J. Llorens Barba (I820-I872). En efecto, Ramón Martí de Eixalá articuló la teoría de la conciencia que fue asumida por Llorens Barba, maestro barcelonés de Francisco Giner de los Ríos y de Marcelino Menéndez y Pelayo. En sentido amplio, este pensamiento se puede vincular a la filosofía escocesa (Hamilton, Reid, Stewart), la presencia de la cual se remonta a los tiempos de Ramón Martí de Eixalá. No se trataba de un filósofo de profesión, sino de un jurista que con su divisa Meditemos, no discutamos enseñó la asignatura de «Ideología», a partir de I835 en la Academia de Ciencias Naturales y Artes de Barcelona, germen de la restauración de la Universidad de Barcelona (I837). Aquel curso -que inauguraba el estudio académico de la filosofía al margen de las instituciones eclesiásticas- presentaba la ideología -terminología tomada en préstamo de los Eléments d'Idéologie del francés Destutt de Tracy-4 como la ciencia de las ideas, entendidas como "hechos de conciencia». Martí de Eixalá establece que la conciencia es el acto de un «yo» operativo, concreto; es el «yo siento, yo veo», en una actitud que más tarde fue asumida por Francisco J. Llorens Barbas.

Gracias al magisterio de Llorens Barba, en Cataluña no arraigó la filosofía krausista, implantada en Madrid a partir de la importación que Julián Sanz del Río hizo del pensamiento de Krause. No deja de ser significativo que Jaime Serra Húnter dibujase un estudio comparativo entre ambas figuras en que contrapone el aspecto psicologista y empírico de Llorens con la dimensión idealista de Sanz del Río, si bien los dos descollaron en su magisterio:

Bonet, Alberto: La conciencia moral del niño: estudios teórico-prácticos acerca de su contenido y de su formación, Barcelona, Eugenio Subirana, I927.

4 García Carrasco, Joaquín: «Reflexiones histórico-pedagógicas ante los "Éléments d’Idéologie” de Destutt de Tracy», Historia de la Educación. Revista Interuniversitaria, núm. I (1982), pp. 219-228.

La filosofía de Francisco Llorens Barba ha sido objeto de diversos estudios, entre los que destacamos los siguientes: Bilbeny, Norbert: «Francesc Xavier Llorens i Barba, filosofia del sentit comú», en Filosofia contemporània a Catalunya, Barcelona, Edhasa, 1985, pp. 177-20I; ANGLÉs Cervelló, Misericòrdia: El pensament de F. Llorens i Barba i la filosofia escocesa, Barcelona, Institut d'Estudis Catalans/Treballs de la secció de filosofia i ciències socials, xxv, I998; Cuscó Clarasó, Joan: Francesc Xavier Llorens i Barba i el pensament filosòfic a Catalunya, Barcelona, Publicacions de l'Abadia de Montserrat, 1999; Llorens I BARBA, Francesc: Filosofia i consciència, estudi i selecció de textos de Joan Cuscó i Clarasó, Barcelona, Publicacions de la Facultat de Filosofia, Universitat Ramon Llull, 2 oro. 
ALBERTO BONET Y SU ESTUDIO SOBRE LA CONCIENCIA MORAL DEL NIÑO (I927):

A PROPÓSITO DE LOS PRIMEROS TRABAJOS SOBRE LA EDUCACIÓN MORAL ... MONSERRAT PAYÁ SÁNCHEZ Y CONRAD VILANOU TORRANO

En buena doctrina krausista como en buena doctrina escocesa, no cabe una actitud radical empírica o sensista. Sin embargo, el espiritualismo de uno y otro son de índole muy diversa. El espiritualismo del profesor de Madrid ha bebido en fuentes germánicas, es una forma de idealismo absoluto, por él llamado armónico. En cambio, el de Llorens es el espiritualismo concreto, de cepa remotamente cartesiana o en todo caso tradicional ${ }^{6}$.

Incluso, el profesor Mirabent ${ }^{7}$ consideraba que la filosofía del sentido común -Llorens Barba tradujo el common sense de Hamilton por la doctrina o filosofía del sentido común- era comparable en Cataluña al idealismo moral propagado desde Madrid por los intelectuales krausistas ${ }^{8}$. Efectivamente, si la orientación pedagógica del krausismo está fuera de cualquier duda, conviene remarcar la vocación educativa de la filosofía de Llorens Barba, tal como aparece al referirse al imperativo categórico como hecho capital de la conciencia moral. En consecuencia, Llorens Barba también hizo -como los krausistas- una apología de la educación en sentido pedagógico moral, según se desprende de las palabras que ponen fin a sus lecciones de filosofía:

En virtud de esto decimos e insistimos, psicológicamente hablando, que el negocio principal de la vida humana no es una mera comunicación de conocimientos que se dan por conceptos, sino que es la educación, la acción de una vida sobre otra vida y esta instrucción precedente no puede tener valor completo como no venga acompañada de esta educación. Reconociendo la ley moral en su carácter absoluto, en su práctica en la perfección moral no vemos otro medio que esta aproximación, este trabajo incesante que el hombre tiene el deber de practicar para acercarse cada día al modelo divino que tenemos de nuestra alma?.

De hecho, esta preocupación por la educación moral ya se encuentra en el pensamiento de Ramón Martí de Eixalá, tal como estudió Cosme Parpal Marqués

6 Serra Húnter, Jaime: Dos figuras universitarias: Sanz del Río y Llorens y Barba, Madrid, Asociación Española para el Progreso de las Ciencias, 1925.

Sobre el profesor Francesc Mirabent y su encaje en la Facultad de Filosofía y Letras de la Universidad de Barcelona, antes y después de la Guerra Civil, se pueden ver las siguientes referencias: Roviró alemany, Ignasi: «Francesc Mirabent i Vilaplana», en Monserrat Molas, Josep y Casanovas, Pompeu (eds.): Pensament i filosofia Catalunya. II: 1924-1939, Barcelona, Inehca/Societat Catalana de Filosofia, 2003, pp. I05-135; Roviró alemany, Ignasi: Estètica i filosofia a Catalunya. Francesc Mirabent, Barcelona, Facultat de Filosofia, Universitat Ramon Llull, 2003; Carcasó, Jordi: "La diversité des cultures (1948) de Francesc Mirabent. Un text inèdit d'una època de tenebres», Temps d'Educació, núm. 45 (2013), pp. 24I-253.

Mirabent, Francesc: «L'escola escocesa i la seva influència en els filòsofs catalans del segle XIX», en Conferències Filosòfiques (1928-1929), Barcelona, Ateneu Barcelonès, 1930, pp. III-I37. Con anterioridad, Mirabent se había ocupado de la filosofía escocesa en su tesis doctoral sobre La estética inglesa del siglo XVIII (Barcelona, Cervantes, 1927). Después de su muerte, se publicaron dos volúmenes que recogían diversos trabajos bajo el título genérico de Estudios estéticos y otros ensayos filosóficos (Barcelona, Csic, I957-1958).

9 Llorens y BARBA, Francisco Javier: Lecciones de filosofía. Explicadas en la Universidad Literaria de Barcelona durante los cursos de 1864-65 y 1867-68, taquigrafiadas por José Balari y Jovany, Barcelona, Facultad de Filosofía y Letras, Universidad de Barcelona, 1920, 3 volúmenes [la cita corresponde al vol. III, Filosofía práctica, lección v, p. 267]. 
ALBERTO BONET Y SU ESTUDIO SOBRE LA CONCIENCIA MORAL DEL NIÑO (I927): A PROPÓSITO DE LOS PRIMEROS TRABAJOS SOBRE LA EDUCACIÓN MORAL ... MONSERRAT PAYÁ SÁNCHEZ Y CONRAD VILANOU TORRANO

- primer catedrático de Psicología de la Universidad de Barcelona- en el trabajo Análisis de la educación moral del hombre: un manuscrito inédito de Martí de Eixalá, que además se incluyó en la revista La Academia Calasancia de Barcelona $^{10}$. Este manuscrito fue de los pocos que se salvaron del fondo de Martí de Eixalà, que en su mayoría fueron destruidos después de su muerte. Se trata de un análisis de la educación moral que persigue impedir que se formen malos hábitos y pasiones antisociales, a la vez que se aspira a excitar los hábitos sociales centrados en los siguientes puntos: familia (amor paternal, filial, conyugal), sociedad (amor a la gloria, pasión por la virtud, amor a la patria) y sentimiento religioso. Se trata de un pequeño manual a fin de fomentar los hábitos y las virtudes con cierto aire estoico que recomienda la moderación de los placeres, programa que sintoniza con los planteamientos de la sociedad liberal del siglo xIx, proclive al moderantismo entre el inmovilismo ultramontano y los conatos revolucionarios.

Como vemos, para la tradición filosófica catalana, la conciencia es la raíz y punto de partida de todo conocimiento y, por consiguiente, acentúa el valor de la intimidad humana. No es extraño, pues, que la filosofía del sentido común -tal como Tomás Carreras Artau presentó en su ensayo sobre Llorens- ${ }^{\text {II }}$ se preocupe más del instrumento, de las condiciones del recto pensar, que de la obra filosófica misma. Entendida de esta manera, la filosofía del sentido común - un movimiento que circuló por toda la Europa del siglo XIX-se configura como una especie de higiene mental y de propedéutica del espíritu, a modo de una verdadera filosofía del «seny» que exige -como paso previo- el diálogo interior consigo mismo. Estructurada la filosofía de Llorens según una dirección fundamentalmente psicológica, su pensamiento se convierte en una filosofía de la conciencia que Alberto Bonet, primero, y Alejandro Sanvisens, después, aplicaron al campo de la educación.

Eso es la conciencia: conocimiento de nosotros mismos, de nuestros actos y afecciones; porque cuando decimos conocimiento de nosotros mismos, o conocimiento que de sí mismo tiene el «yo» se conoce siempre modificado, se conoce sintiendo o deseando, esperando o temiendo; no se conoce de una manera abstracta, ni de una manera concreta sino viviendo, y semejante vida se expresa por las palabras sentir, conocer y querer ${ }^{12}$.

Así pues, resulta lógico que los discípulos de Tomás Carreras Artau, como Alberto Bonet y Alejandro Sanvisens, asumiesen el tema de la conciencia que

1o Parpal i Marqués, Cosme: Análisis de la educación moral del hombre: un manuscrito inédito de Martí de Eixalá, Barcelona, Imprenta de Pedro Ortega, 1920, 64 pp.

" CARreras i ArTau, Tomás: «Xavier Llorens i Barba», en Introducció a la història del pensament filosòfic a Catalunya, Introducció a la bistòria del pensament filosòfic a Catalunya, Barcelona, Llibreria Catalònia, 1931, pp. 227-252.

${ }_{12}$ LloRENS Y BARBA, Francisco Javier: Lecciones de filosofía. Explicadas en la Universidad Literaria de Barcelona durante los cursos de I864-65 y 1867-68, taquigrafiadas por José Balari y Jovany..., op. cit., vol. I, Psicología empírica, lección viII, pp. II6-II7. De este modo, se puede hablar de una conciencia subjetiva y de otra conciencia objetiva. Mientras en la primera predomina la actividad racional, la conciencia objetiva depende de la actividad de los órganos sensibles y es la que empleamos cuando decimos «veo esto». 
ALBERTO BONET Y SU ESTUDIO SOBRE LA CONCIENCIA MORAL DEL NIÑO (I927): A PROPÓSITO DE LOS PRIMEROS TRABAJOS SOBRE LA EDUCACIÓN MORAL ... MONSERRAT PAYÁ SÁNCHEZ Y CONRAD VILANOU TORRANO

se aplica a la teoría del conocimiento (al huir del empirismo, del escepticismo y del idealismo) y a la filosofía práctica (conciencia moral de la que dependen el sentimiento moral y el juicio moral). Desde aquí se entienden las aportaciones del profesor Tomás Carreras Artau reunidas en el Esbozo de una morfología de la conciencia moral (1930), en que a partir de tal objeto de estudio establece una etología que plantea diferentes tipologías morales.

Se trata de un trabajo que se publicó en la revista Philosophia Perennis (1930) en que el autor, después de examinar los antecedentes doctrinales de la conciencia moral (tradición socrática, teólogos moralistas, místicos, psicología genética, psicología individual y diferencial, psicología colectiva, psicología étnica, psicología criminológica, psicología patológica), ensaya una clasificación sistemática de las formas de la conciencia moral (derivadas del proceso genético, formas de conciencia moral individual, formas de la conciencia moral colectiva, formas de la conciencia moral del hombre civilizado, formas de la conciencia moral del hombre primitivo, formas de la conciencia moral normal, formas de la conciencia moral anormal). Después de describir algunas situaciones características de la conciencia moral, establece una tipología moral en un elenco amplio de posibilidades, que se pueden aplicar a la vida cotidiana -el arte de conocer y tratar a las personas- con claras intenciones pedagógicas.

El conocimiento de los tipos morales ha de ser también una labor previa de todo intento educativo. Pero así como al común de los hombres, para los fines de la convivencia, le basta conocer y acatar la realidad moral del prójimo, tal como es, no siéndolo lícito verla de otra manera; el educador ha de conocer y tomar los susodichos tipos morales sólo como un punto de partida, pues aspira a convertir el tipo moral empírico en un tipo ideal. Para realizar semejante transformación se vale de aquel conjunto de procedimientos de carácter eminentemente ético, comprendidos bajo la denominación genérica de corrección. Bien entendido que la corrección exige un tratamiento especial para cada tipo moral definido. Resumiendo, podemos afirmar que la Morfología de la conciencia moral, complementada con la Tipología moral o Etológica, de la cual es un indispensable anexo el Arte de conocer y tratar a las personas, imprime a la Ética un triple carácter universal, realista y profundamente humano a la vez ${ }^{13}$.

Además, esta tipología moral -de indudables aplicaciones pedagógicas- sirve para tratar y conocer a las personas, sobre la base de una filosofía que no se basa en el yo (idealismo), ni en el nosotros (sociologismo), sino en el tú, es decir, en el otro. Mucho antes de que se pusiese de moda la filosofía interpersonal de la alteridad (Lévinas), Tomás Carreras Artau escribió: «Le fondement d'une philosophie d'autrui est une nécessité philosophique et vital de notre temps ${ }^{\text {I4 }}$. Llegados a este

13 Carreras Artau, Tomás: «Esbozo de una Morfología de la conciencia moral», en Escritos filosóficos. I. Escritos doctrinales, Barcelona, Csic-Instituto Luis Vives, I966, vol. I, p. 313.

${ }^{14}$ Carreras Artau, Tomás: «Philosophie du moi, du nous et d'autrui» (Comunicación al XI Congreso Internacional de Filosofía, Bruselas 1953), en Estudios filosóficos. I. Escritos doctrinales, op. cit., II5. 
ALBERTO BONET Y SU ESTUDIO SOBRE LA CONCIENCIA MORAL DEL NIÑO (I927): A PROPÓSITO DE LOS PRIMEROS TRABAJOS SOBRE LA EDUCACIÓN MORAL ... MONSERRAT PAYÁ SÁNCHEZ Y CONRAD VILANOU TORRANO

punto, puede ser conveniente recordar que Luis Cuéllar, en su síntesis sobre el pensamiento de Tomás Carreras Artau, apuntaba lo siguiente:

El Dr. Carreras defendía la necesidad de constituir lo que él llamaba una filosofía del otro, distinta de la filosofía del yo, propia del idealismo moderno, que acentúa la autonomía del mismo, y distinta también de la filosofía del nosotros, propia de la mencionada escuela sociológica, que exagera el carácter de presión que sobre el individuo ejerce la sociedad, imponiéndole una moral de vigencia sólo momentánea. La filosofía del otro supone entre los hombres una relación interpersonal, basada en la libertad e inscrita dentro de un horizonte de valores universales y eternos ${ }^{15}$.

En realidad, la existencia de una filosofía autóctona en Cataluña fue defendida por Tomás Carreras Artau en su Introducció a la bistòria del pensament filosòfic a Catalunya (193I ${ }^{16}$. Según parece, a la muerte de Llorens Barba en I872 la filosofía tomista orilló la filosofía escocesa de manera que cuando Tomás Carreras Artau cursaba sus estudios en la Universidad de Barcelona (I894-1900) la presencia de la filosofía del sentido común se había evanecido totalmente. "Ni en l’obra ni en les explicacions del professor -Carreras se refiere a las clases de Metafísica- es mencionava per res el nom del doctor Llorens o del seu mestre Martí de Eixalà, ni es feia la més lleu al·lusió a aquell interessant període filosòfic» ${ }^{17}$. Juntamente con Jaime Serra Húnter y Cosme Parpal, Tomás Carreras Artau hizo muchos esfuerzos para recuperar una tradición que se había perdido a fines del siglo xIx y de la

is Cuéllar, Luis: «In Memoriam», Convivium, núm. I (1956), p. 8.

16 Carreras Artau, Tomás: Introducció a la història del pensament filosòfic a Catalunya..., op. cit. Este libro lleva la siguiente dedicatoria: «A la memòria del Dr. Xavier Llorens i Barba (I820I872) vir bonus, filòsof i professor de raça en qui la vida i la doctrina concorden admirablement. El seu mestratge perdurarà en el record, encara vivent, de la seva vida exemplaríssima i a través de les seves Lecciones de Filosofía, publicades per la Facultat de Filosofia i Lletres de la Universitat de Barcelona». En el ejemplar que se conserva en la Universidad de Barcelona procedente del legado Mirabent, este profesor -catedrático de Estética, a quien substituyó Alejandro Sanvisens cuando murió- añadió al final, en notas manuscritas a lápiz, lo siguiente: «Per la meva banda, no he combatut els filòsofs catalans o renaixents. He dit que la manera de plantejar els problemes no interessa en el nostre temps i demés no poden constituir una filosofia catalana; la manera que Vives entén el sentit comú no és la manera escocesa, ni l'abast metafísic ni el mètode ni la rel espiritual. Hi ha altres influències que condicionen el sentit del common sense. Descartes, Leibniz, Kant. L’Edat Mitjana és interessant sempre, i és clar que tots els problemes hi troben precursors; però l'originalitat absoluta en Filosofia no és possible trobar-la més que en el mode de replantejament dels problemes. I tots sabem que per això la Filosofia necessita de totes les altres activitats humanes. Per això, un medieval no pot ésser pròpiament un precursor. En canvi pot ésser-ho un grec... El resultat de la recerca del D. C. (Doctor Carreras) és que Llull i Vives poden ésser presos com els fundadors veritables de la filosofia catalana. D'acord. Però Catalunya va morir civilment en el segle XvıII, al començar, i després de dos segles de total decadència intel-lectual. Reneix modestament a meitat del segle xIx, i no pot reprendre altra tradició que el record gloriós de la seva passada grandesa. No més record. Ara, ha de crear un pensament que reflecteixi la seva modalitat d'avui. Qui comencen a crear-la és Balmes i és Llorens».

${ }_{17}$ Carreras Artau, Tomás: La meva Girona. Memòries de Tomàs Carreras i Artan, prefaci de Narcís-Jordi Aragó, introducció, edició i notes a cura de Pep Vila, Girona, Ajuntament de Girona/ Institut d'Estudis Gironins, 200I, p. I55. 
ALBERTO BONET Y SU ESTUDIO SOBRE LA CONCIENCIA MORAL DEL NIÑO (I927): A PROPÓSITO DE LOS PRIMEROS TRABAJOS SOBRE LA EDUCACIÓN MORAL ... MONSERRAT PAYÁ SÁNCHEZ Y CONRAD VILANOU TORRANO

que Alejandro Sanvisens fue, igualmente, un decidido valedor. Antes de concluir este apartado, conviene poner de relieve que Cosme Parpal Marqués (I878-I923), catedrático de Psicología de la Universidad de Barcelona desde I9I4, además de colaborar en la edición de las Lecciones de Filosofía de Francisco J. Llorens Barba, contribuyó a recuperar su filosofía encargándose de la transcripción del ejercicio escrito de Llorens en la oposición a la Cátedra de «Filosofía y su Historia» de la Universidad de Barcelona, realizado en Madrid el I8 de julio de $1847^{18}$.

\section{El Seminario de Ética de Tomás Carreras Artau}

Como bien hemos anunciado, Tomás Carreras Artau (I879-1954) fue catedrático de Ética de la Universidad de Barcelona desde el año I9I2, promoviendo el Archivo de Etnografía y Folklore de Cataluña que empezó su singladura en i9i5. Con anterioridad había opositado sin éxito a la cátedra de Derecho Natural de la Universidad de Oviedo (1903), ya que en Barcelona la sección de Filosofía no se abrió hasta el año ıэıo. En la Universidad de Barcelona, Tomás Carreras Artau había permanecido durante cinco años, entre I895 y I90I, tal como refleja en sus memorias, años que aprovechó para licenciarse en Derecho (I895-I90I) y Filosofía y Letras (I895-I899), si bien en aquel momento todavía no se había implantado en la ciudad Condal la especialidad de Filosofía. Durante el año académico i9oII902 residió en Madrid para cursar los correspondientes estudios de doctorado. Hay que añadir que siempre fue un alumno excepcional y que así lo reflejan sus expedientes académicos tanto en el Instituto como en la Universidad. Y a pesar de la languidez de la vida académica del momento, los primeros síntomas de renovación se dejaban sentir en el viejo claustro universitario ${ }^{19}$. Llegó a la cátedra cuando contaba treinta y tres años de edad y gozaba de una larga experiencia en el ejercicio profesional de la abogacía.

Desde primera hora, Carreras pensó en organizar a su alrededor un conjunto de actividades docentes e investigadoras de manera que la cátedra se convirtió en el centro neurálgico de la vida académica. En este sentido, el año I9I2 -coincidiendo

18 Parpal Marquès, Cosme: «Una pàgina inèdita del Dr. Llorens. De la unidad de la filosofía», Anuari de la Societat Catalana de Filosofia, núm. I (1923), pp. 315-321. Además de publicar una monografía sobre los Antecedentes de la escuela filosófica catalana del siglo XIX (Barcelona, Imprenta Cosmas y Portavella, 1914), se responsabilizó de la edición de un texto de Ramón Martí de Eixalá titulado Análisis de la educación moral del hombre: un manuscrito inédito de Martí d'Eixalá, como ha sido comentado más arriba.

19 En sus Memorias escribió con relación a la Universidad lo siguiente: «No tenia amics ni enemics, perquè no tenia ambicions. No obstant, no tot era buidor oficial; hi havia un cert esperit corporatiu que es nodria principalment del record del passat, del nom gloriós d'alguns dels seus professors i de la persistència de les etiquetes acadèmiques, les quals, encara que avui, amb el canvi dels costums, sembli el contrari, contribuien poderosament aleshores a formar al voltant del professorat una atmosfera de consideració social que transcendia fins als mateixos alumnes. Els catedràtics anaven a la Universitat de levita i amb barret de copa, i eren uns senyors, a l'aula, explicaven amb toga i birreta...» (CARRERAs i Artau, T.: La meva Girona. Memòries de Tomàs Carreras i Artan..., op. cit., p. I22). 
ALBERTO BONET Y SU ESTUDIO SOBRE LA CONCIENCIA MORAL DEL NIÑO (I927): A PROPÓSITO DE LOS PRIMEROS TRABAJOS SOBRE LA EDUCACIÓN MORAL ... MONSERRAT PAYÁ SÁNCHEZ Y CONRAD VILANOU TORRANO

con la obtención de la cátedra de Ética- elaboró dos trabajos que daban cuenta y razón del programa de su asignatura, del método de enseñanza y de los proyectos y orientaciones que ofrecía para su expansión y desarrollo ${ }^{20}$.

Después que Carreras Artau llegara a la cátedra de Ética en I9I2, Jaime Serra Húnter obtuvo la de Historia de la Filosofía al año siguiente, a la que había opositado -sin éxito final, pero después de la realización de magníficos ejerciciosAgustín Calvet, conocido con el seudónimo de Gaziel, que había de dirigir La Vanguardia, convirtiéndola en un periódico de referencia ${ }^{21}$. Dejando al margen este episodio de las oposiciones, hay que resaltar que desde un primer momento, se abrió entre ambos catedráticos -Tomás Carreras Artau y Jaime Serra Húnter- una cierta distancia intelectual que se agudizó con el paso de los años y la llegada de nuevos profesores como Pedro Font i Puig (I924) y Joaquín Xirau (I928). Mientras Font i Puig -a pesar de mantener su independencia- se mostró más próximo a Tomás Carreras Artau, Joaquín Xirau había formado parte, desde su etapa de estudiante, del núcleo cercano a Serra Húnter, de quien fue discípulo y seguidor.

No cabe la menor duda de que Tomás Carreras siempre defendió la importancia del diálogo verbal en el trabajo de cátedra que contemplaba la realización de Seminarios, en los que la colaboración entre maestro y alumno se hacía más evidente. Tanto es así que según Carreras la meditación y el diálogo constituyen dos momentos indispensables del arte de la filosofía que -desde una perspectiva pedagógica- se resuelve en clave dialógica porque «enseñar es aprender»"22. Queda claro que Tomás Carreras Artau llegó a la cátedra de Ética con voluntad de servicio, consciente del papel que la cultura reservaba -más allá de la simple preparación de profesionales- a la Universidad. De conformidad con esta manera de hacer, nunca utilizó la cátedra para ostentación y lucimiento personal. Tal actitud hizo que criticara la manera de actuar de José Ortega y Gasset que, en unas conferencias dictadas en Barcelona el año 1929 con ocasión del Congreso organizado del 20 al 27 de mayo de aquel año por la Asociación Española para el Progreso de las Ciencias, coincidiendo con la inauguración de la Exposición Internacional, utilizó la filosofía como espectáculo. Además, la actividad de la cátedra había de ir acompañada de una serie de publicaciones que -en sintonía con la orientación del catedrático titular- sirviese para difundir pensamientos e ideas afines.

En este sentido, destacamos la serie de notas y materiales para la Historia de la Ética que se publicaron en el marco de las actividades del Seminario de Ética: I.

20 Carreras i Artau, Tomás: Programa de ética con indicaciones sobre el método de cátedra que presenta al Tribunal de oposiciones a la Cátedra de Ética de la Universidad de Barcelona, Madrid, [s. n.], I9I2, 39 pp.; CARRERAS I ARTAU, Tomás: Ética hispana: orientaciones y proyectos de expansión de Cátedra. Informe que presenta al Tribunal de oposiciones a la Cátedra de ética de la Universidad de Barcelona, Madrid, [s. n.], 1912, 78 pp. [Este último trabajo se incluyó en la edición de sus Estudios filosóficos. I. Escritos doctrinales, op. cit., pp. 265-278].

${ }_{21}$ GazIEL: Tots els camins duen a Roma. Història d'un destí (I893-19I4). Memòries II, Barcelona, Edicions 62, I98I, pp. 266-268.

22 Carreras i Artau, Tomás: Introducció a la bistòria del pensament filosòfic a Catalunya, op. cit., p. 189. 
ALBERTO BONET Y SU ESTUDIO SOBRE LA CONCIENCIA MORAL DEL NIÑO (I927): A PROPÓSITO DE LOS PRIMEROS TRABAJOS SOBRE LA EDUCACIÓN MORAL ... MONSERRAT PAYÁ SÁNCHEZ Y CONRAD VILANOU TORRANO

Joaquín Carreras Artau, El concepto de ley interior de San Pablo, 1927; 2. Aniceto Olano Galarraga, La voluntad moral en San Buenaventura, 1927; 3. Ramón Roquer Vilarrasa, La moral contingentista de E. Boutroux, 193I. Estas tres obras llevaban el pie de imprenta de la Facultad de Filosofía y Letras de la Universidad de Barcelona, indicando su vinculación a la cátedra de Ética. En esta misma dirección, aunque publicado en la imprenta Subirana de Barcelona, se puede insertar el libro de Alberto Bonet La conciencia moral del niño: estudios teórico-prácticos acerca de su contenido y de su formación, aparecido en 1927.

Sin ir más lejos, Alberto Bonet (I894-1974) -doctorado en teología (1917) y en filosofía (1930)- había sido alumno de Tomás Carreras durante el curso 1919-1920, habiéndose responsabilizado durante dos años de la dirección espiritual de los niños del asilo de San Juan de Dios de Barcelona. En aquel curso, siendo alumno de la asignatura de Ética, aportó una memoria sobre la vida moral de aquellos niños, a los que tuvo de abandonar para asumir otras labores dentro de la diócesis. El mismo Tomás Carreras Artau reconocía que mosén Bonet había elaborado este trabajo a partir de una observación directa de los niños, a la par que había colaborado en el Archivo de Psicología que había recogido más de tres mil cartas de los niños a los Reyes que hoy se encuentran depositadas en el archivo de la Facultad de Filosofía de la Universidad de Barcelona y que habían de servir para estudiar la mentalidad infantil.

Sin embargo, no es menos verdad que Carreras Artau -que estimaba la tradición y la historia- chocó con los vientos de renovación que aportó Joaquín Xirau. Estos dos gerundenses -Carreras (I879) nació en Gerona y Xirau (I895) en Figueras- estaban separados por unos cuantos años y, lo que es más destacado, por una concepción universitaria y política bien diferenciada. No en balde, Xirau enlaza -gracias a su amistad con M. B. Cossío-con el espíritu de la Institución Libre de Enseñanza, aspecto no compartido por Carreras, siempre alejado de los discípulos de Giner de los Ríos y defensor de la filosofía de Llorens Barba.

Según Carreras Artau, el principio que debía regir el funcionamiento de una cátedra universitaria no era otro que el de la cooperación científica, ya que además de una dimensión productiva supone un aspecto pedagógico, que siempre surge de cualquier trabajo ordenado y sistemático. «Concebimos la cátedra a que aspiramos, a manera de una Cooperativa de producción intelectual... No sólo de cooperación, sino también de relación aspiraríamos a que fuese la Cátedra». Pero no acaba aquí la cosa porque Carreras -que conocía los programas de extensión universitaria que tenían lugar en aquellos momentos inspirados en los modelos de cultura popular surgidos en Inglaterra- dejó bien patente que no se trataba de una extensión universitaria, sino de una expansión universitaria.

Resulta evidente que la polémica en torno a la posible existencia de una escuela filosófica catalana es una cuestión disputada que ha llegado hasta nuestros días. El reciente libro de Xavier Serra sobre la filosofía en la cultura catalana pone al descubierto la falta de entidad de esta tradición, la del sentido común, que a su vez constituía un fenómeno ciertamente continental que no puede limitarse al 
ALBERTO BONET Y SU ESTUDIO SOBRE LA CONCIENCIA MORAL DEL NIÑO (I927):
248 A PROPÓSITO DE LOS PRIMEROS TRABAJOS SOBRE LA EDUCACIÓN MORAL ...
MONSERRAT PAYÁ SÁNCHEZ Y CONRAD VILANOU TORRANO

caso catalán ${ }^{23}$. Sea como fuere, y de acuerdo con el análisis que hizo Joaquín Carreras Artau, esta tradición filosófica -iniciada por Ramón Martí de Eixalá y consolidada por Francisco J. Llorens $\mathrm{Barba}^{24}$ se caracteriza por las siguientes notas: un talante conservador a fin de superar el abismo abierto por la Ilustración entre fe y razón; el rechazo de la razón como fuente exclusiva del pensamiento, de manera que se aleja del racionalismo, del escepticismo y del idealismo; una teoría del conocimiento realista basada en los datos suministrados por la sensibilidad y, finalmente, una actitud de ascendencia socrática que enfatiza la conciencia que es capaz de captar la existencia de una ley moral que refleje la presencia divina.

Como venimos señalando, la polémica en torno a la existencia o no de una escuela filosófica catalana fue en su momento importante, superando el ámbito estrictamente académico y llegando a las páginas de la prensa diaria con la conocida participación de Eugenio d'Ors ${ }^{25}$. De hecho, y frente a los esfuerzos de Tomás Carreras Artau para restablecer esta tradición filosófica, Joaquín Xirau negó la viabilidad de una filosofía catalana, si bien aceptó la coincidencia, en ciertos momentos de la historia, de algunos nombres eminentes que participaron puntualmente en los debates filosóficos.

Del periodismo de la época sobresalen las ácidas y corrosivas críticas de Josep Pla contra la filosofía de Llorens Barba, comentarios que el escritor ampurdanés mantuvo -a manera de notas dispersas- en diferentes lugares de su obra comple$\mathrm{ta}^{26}$. Al fin y al cabo, Josep Pla y Tomás Carreras Artau-procedentes de las tierras gerundenses- fijaron interpretaciones bien diferentes sobre el pasado cultural de la ciudad de Gerona y, lo que tampoco es irrelevante, discreparon abiertamente sobre la condición y posibilidad de la filosofía de Llorens ${ }^{27}$.

Probablemente uno de los juicios más ponderados sobre esta cuestión es la emitida por Joaquín Carreras Artau -profesor de filosofía de Alejandro Sanvisens

23 SErra, Xavier: La filosofía en la cultura catalana, Catarroja-Barcelona, Editorial Afers, 2013.

24 Carreras i Artau, Joaquín: «Un maestro barcelonés de Menéndez y Pelayo: Javier Llorens y Barba», Revista de Filosofía, xv, núm. 58-59 (1956), pp. 445-463. Justamente aquel año de 1956, Joaquín Carreras Artau participó en el ciclo de conferencias organizado por la «Cátedra Ciudad de Barcelona» con motivo del centenario del nacimiento de D. Marcelino Menéndez Pelayo. Según comenta Pere Lluís Font fue a partir de esta fecha, y probablemente al haber estudiado la influencia de Llorens Barba sobre Menéndez y Pelayo, cuando se acentuó su interés por los pensadores catalanes del siglo XIX.

${ }_{25}$ Esta historia fue documentada por Jaime Serra Húnter en «Xavier Llorens i Barba. Estudis i carrera professional. La seva actuació docent», Arxius de l'Institut de Ciències, any Ix, fascicle únic (1937). Más recientemente ha sido explicada con mucha precisión por Misericòrdia Anglès en el capítulo tercero («Publicació pòstuma de l'obra de Llorens») del libro Elpensament de F. Xavier Llorens i Barba i la filosofia escocesa, op. cit., pp. 8I-IIz.

${ }_{26}$ PLA, Josep: Obra completa, Barcelona, Destino, 1968, vol. x, Tres biografies. «Francesc Pujols. Notes», pp. 46I-465 («Prossegueix la lectura») y pp. 480-485 («A Vilafranca del Penedès»); PLA, Josep: Obra completa, Barcelona, Destino, 1982, vol. XL, A Vilafranca del Penedès. Dos pols del pensament català vuitcentista, pp. 39-42.

${ }_{27}$ Un ejemplo de esta discrepancia, se detecta en el comentario de Tomás CARRERAs ARTAu al libro sobre Gerona de Josep Pla (Nota bibliográfica sobre: «Josep Pla: Girona. Un llibre de records. Barcelona, Ed. Selecta, 1952», Anales del Instituto de Estudios Gerundenses, viI [1952], pp. 376-379). 
ALBERTO BONET Y SU ESTUDIO SOBRE LA CONCIENCIA MORAL DEL NIÑO (I927):

A PROPÓSITO DE LOS PRIMEROS TRABAJOS SOBRE LA EDUCACIÓN MORAL ... MONSERRAT PAYÁ SÁNCHEZ Y CONRAD VILANOU TORRANO

durante sus estudios de bachillerato-, leído a la luz de las interpretaciones que ha hecho Pere Lluís Font que -después de reconocer los méritos de esta filosofía del sentido común- ${ }^{28}$ señala como limitación capital que se tratase de una filosofía de tono menor, falta de espíritu intelectual.

Ciertamente que el profesor Alejandro Sanvisens era conocedor de todo este embrollo y de la polémica que acompañó la edición de las lecciones filosóficas de Llorens Barba. A menudo en sus clases o conversaciones privadas recordaba cómo Eugenio d'Ors - despechado con la Universidad desde que perdió las oposiciones a la cátedra de Psicología que obtuvo, finalmente, Cosme Parpal- se avanzó desde el Consejo de Pedagogía de la Diputación de Barcelona a la edición que estaba realizando la Facultad de Filosofía y Letras sobre el manuscrito que había elaborado José Balari Jovany, profesor de Taquigrafía de la Universidad ${ }^{29}$. Finalmente las Lecciones de Filosofía aparecieron, en tres volúmenes, el año 1920. Parece ser que en 1875 ya se contaba con el compromiso de la casa Medina y Navarro de Madrid para publicar esta obra, gracias a los buenos oficios de Francisco Giner de los Ríos, que también había recibido el magisterio de Llorens en Barcelona. Sin embargo, el original -que había de llevar un estudio o discurso preliminar de José de Letamendi, catedrático de la Facultad de Medicina, el discípulo preferido de Llorens- no se libró en el momento oportuno. Este conjunto de circunstancias determinó que la aparición de las Lecciones de Filosofía se retrasara hasta bien entrado el siglo xx.

Pero al margen de controversias, constatamos que el profesor Alejandro Sanvisens -al dar como buenas las tesis de su maestro Tomás Carreras Artau-confió en la presencia de una filosofía propia y característica de Cataluña que, además, supo vivificar con las aportaciones de la cibernética. Esta filosofía catalana fue expuesta por el profesor Sanvisens en diversas ocasiones, a la vez que la identificaba como filosofía del sentido común. Para ilustrar lo que decimos, baste recordar el seminario que impartió, el año 1965, en el Instituto Municipal de Historia de Barcelona sobre Historia de la filosofía barcelonesa, desde Balmes y la corriente de Cervera hasta Tomás Carreras Artau. Quienes firmamos este trabajo, recordamos diversas conferencias que impartió sobre la cuestión, en especial la que pronunció sobre «Javier Llorens Barba y la filosofía del sentido común», el 28 de

28 Joaquín Carreras Artau abordó el tema de «La filosofía escocesa en Cataluña», en la lección inaugural del curso 1958-1959 en la Sociedad Catalana de Estudios Históricos del Institut de Estudis Catalans, texto que permaneció inédito hasta que Pere Lluís Font lo incorporó al libro Centenari Joaquim Carreras i Artan (1894-1994), Barcelona, Departament de Cultura de la Generalitat de Catalunya, 1994, pp. 15-29. Con anterioridad, Joaquín Carreras Artau había publicado una versión edulcorada sobre esta cuestión: La filosofía universitaria en Cataluña durante el segundo tercio del siglo XIX, Barcelona, Csic, I964. También puede consultarse: Lluís FonT, Pere: «Joaquim Carreras i Artau», en Monserrat Molas, Josep y Casanovas, Pompeu [eds.]: Pensament i filosofia Catalunya. II: 1924-1939, Barcelona, Inehca/Societat Catalana de Filosofia, 2003, pp. I44-I45.

29 Llorens Barba, Francesc X.: La Metafísica, Barcelona, Consell de Pedagogia de la Diputació de Barcelona, [1918?]. Durante la Segunda República, apareció otra obra de divulgación sobre la filosofía de Francisco J. Llorens Barba: Iniciació a la filosofia: apunts del curs de filosofia de 1867, de la unitat de la filosofia, del pensament filosòfic, Barcelona, Barcino, 1933. 
enero de 1982 en el Ateneo Barcelonés, en el marco del ciclo «Filósofos catalanes de los siglos XIX y xx» organizado por la Sociedad Catalana de Filosofía, de la que se conserva el correspondiente registro sonoro. Francisco J. Llorens Barba fue un activo socio del Ateneo, colgando de las paredes de su biblioteca -todavía hoyuno de los pocos retratos pintados de Llorens. El doctor Sanvisens nos recordaba a menudo que Llorens Barba era contrario a dejarse retratar, de manera que esta pintura, propiedad del Ateneo barcelonés, constituye una excepción que ha dado pie a todo tipo de interpretaciones psicológicas y caracteriológicas. En fin, nos encontramos -más allá de la discusión histórica y filosófica- ante una manera de pensar que enfatiza y destaca el papel de la conciencia, elemento capital para el desarrollo de los estudios sobre la educación moral, una temática que en la Universidad de Barcelona se enraíza en el siglo XIx y que tuvo magníficos exponentes en el siglo xx como el estudio de Alberto Bonet, que nos ocupa en este artículo.

\section{Alberto Bonet y la conciencia moral del niño}

Adelantado a la época, Albert Bonet supo conjugar sus conocimientos psicológicos y pedagógicos con el «telos» católico al que se dirige como sacerdote. Así, en su pensamiento se pueden encontrar múltiples referencias provenientes de las más dispares disciplinas, incluida la teología. Éstas dan prueba de la amplia formación teórica y pluridisciplinar de este autor, tal como los abundantes ejemplos extraídos de su experiencia y los análisis que les siguen muestran sus capacidades para la observación y la reflexividad. Así, su obra contiene una propuesta de explicación teórica sobre el desarrollo de la conciencia moral y religiosa -ambas en íntima relación para su autor, como mostraremos más adelante-, aderezada con propuestas metodológicas y orientaciones normativas -que abarcan tanto la educación escolar como la familiar e, incluso, la social-, y hacen que la lectura de esta obra -publicada en 1927, cinco años antes que El criterio moral en el niño, de Jean Piaget- resulte, más de ochenta años después, relativamente actual en muchos aspectos, siempre interesante desde la perspectiva histórica y especialmente estimulante para reforzar algunas de las elaboraciones teórico-prácticas que orientan en la actualidad la educación moral y en valores.

\section{I. Principios pedagógicos}

Empezaremos por presentar el marco pedagógico en el que Bonet se sitúa por considerar que son los instrumentos que utiliza para, a la vez, comprender el fenómeno del desarrollo de la conciencia moral en el niño, y revisar las orientaciones práctico-normativas que contribuyen, a su entender, a tal desarrollo. Inevitablemente perderá fuerza en esta exposición ya que en la obra este marco subyace a cada afirmación, situación de experiencia u orientación metodológica. 
ALBERTO BONET Y SU ESTUDIO SOBRE LA CONCIENCIA MORAL DEL NIÑO (I927): A PROPÓSITO DE LOS PRIMEROS TRABAJOS SOBRE LA EDUCACIÓN MORAL ... MONSERRAT PAYÁ SÁNCHEZ Y CONRAD VILANOU TORRANO

Bonet parte de una pedagogía realista y, en consecuencia, necesariamente pluralista: la educación, también la moral, ha de ser personalizada. Cada niño es único y diferente, con sus potencialidades y limitaciones, a las que cabe dar respuesta desde lo educativo ${ }^{30}$. Dicho de otra manera: el ideal de máximo desarrollo es particular a cada niño y la educación tiene el deber de aproximarse a ese ideal. En consonancia, no sería erróneo situar también el pensamiento de Bonet cercano a cierto idealismo pedagógico en el sentido de que la educación debe conducir o acompañar el proceso de optimización de las capacidades de cada persona, según expresó Juan Mantovani en su libro Educación y plenitud bumana, cuya primera edición data de $1933^{3 \mathrm{i}}$.

El autor construye, así, un ajustado equilibrio entre ambos polos, realismo e idealismo, un aspecto interesante de destacar. Desde esta perspectiva, afirma la importancia de los procesos de autoconocimiento en la educación moral, dimensión central por lo que implica de desarrollo de la autonomía y que constituye uno de los pilares de los actuales planteamientos de educación moral y en valores. El sentido que concede Bonet a este máximo desarrollo es, sin embargo, tanto individual como social: para sí mismo y para los otros, la sociedad, superando así los riesgos de una hipertrofia del yo al vincularlo a la alteridad, aspecto ya presente en la filosofía de Tomás Carreras Artau.

La significatividad de los aprendizajes es el segundo principio que recogemos. Para Bonet, ni educación es sinónimo de instrucción ni es irreductible a ella. La adquisición de contenidos culturales influye positivamente en la educación moral, pero por sí sola es insuficiente para la formación de personas éticas y moralmente responsables -también de católicos-. La acción educativa debe tener por horizonte la comprensión de lo que se transmite, sobre lo que el niño ha de trabajar desarrollando esquemas mentales de organización y sistemas de relaciones que converjan en la creación unitaria de sentido. Para ello, es fundamental conectar con los intereses evolutivos y personales del niño: sus gustos, curiosidades, también sus sueños, que sólo pueden ser conocidos -personalización y realismoa través de una observación directa, atenta y cariñosa, del niño en situaciones espontáneas, de juego, mediante conversaciones informales o formales... No en balde, el método observacional -de base realista y trasfondo aristotélico- era uno de los preferidos por Tomás Carreras Artau, que se sirvió del mismo para dar solidez a los trabajos del Archivo de Etnografía y Folklore de Cataluña. Del mismo modo, la actividad intelectual por sí sola tampoco es suficiente, necesita de la estima y de la acción -voluntad de aplicar lo adquirido-. Llegamos así al tercer principio pedagógico que destacamos, el enfoque integral de la educación moral y también la religiosa que ha de conjugar afecto, comprensión y voluntad.

30 Utilizaremos el masculino puesto que en aquella época se acostumbraba a realizar separación en función del género y los centros donde ejerció el Pbro. Albert Bonet eran de niños.

${ }_{31}$ Mantovani, Juan: Educación y plenitud humana, Buenos Aires, M. Gleizer, 1933. Cuando el pedagogo Juan Roura-Parella, que formaba parte del círculo intelectual próximo a Joaquín Xirau, publicó en el exilio (1940) su tesis Educación y Ciencia (que se había defendido en la Universidad de Barcelona el año 1937), Mantovani la saludó de una manera entusiasta, introduciendo las correspondientes referencias en las posteriores ediciones de este clásico de la pedagogía científico-espiritual. 
ALBERTO BONET Y SU ESTUDIO SOBRE LA CONCIENCIA MORAL DEL NIÑO (I927): A PROPÓSITO DE LOS PRIMEROS TRABAJOS SOBRE LA EDUCACIÓN MORAL ... MONSERRAT PAYÁ SÁNCHEZ Y CONRAD VILANOU TORRANO

Por otra parte, y de acuerdo con la argumentación de Bonet, la persona es un ser en relación. Por consiguiente, la acción educativa debe tener presentes los diferentes grupos de pertenencia -familia, grupo, escuela y sociedad- a fin de optimizar sus posibles efectos educativos, tanto como recurrir a los diferentes agentes, personales y no personales -madres y padres, iguales, sacerdotes, vecinos, medios de información y clase política- para, persiguiendo los mismos objetivos, sumar esfuerzos y formar a la infancia de una manera más plena y mejor que, en el pensamiento de su autor, significa más auténtica, consciente y querida, valiéndose del ejemplo.

\subsection{Lo moral y lo religioso: diferencia entre dominios}

Conviene precisar que Bonet afirma que se trata de ámbitos distintos, pero íntimamente relacionados: la religión -todas las religiones- configura un código moral; la moral, por su parte, se dirige al sí mismo y a los demás. También la religión que, como nota diferencial, aporta, además, la experiencia completa de lo trascendente: se dirige a Dios. En consecuencia, lo religioso es superior a lo moral, puesto que lo incluye y lo supera. Así, afirma también que una sociedad que no hiciera ninguna opción religiosa tendería a bajar en moralidad. Dada su condición de sacerdote, la dirección o el contenido material del dominio religioso son nítidos: la doctrina y el ideal católicos. Sin embargo, no por ello deja nuestro autor de dedicar cierto número de páginas a intentar demostrar, mediante razonamientos, que no sólo la religión católica es «la» religión por excelencia, sino que también lo es su código moral. Así, por ejemplo, arguye contra la posibilidad de ser una persona conscientemente atea y moral a la vez. En su opinión, si alguien se considera a sí mismo moral -y lo es- y ateo a la vez, es sencillamente porque no tiene conocimiento pleno de lo que implica ser ateo. En otras palabras, no es real y auténticamente ateo. Éstos no tienen la obligación de seguir los preceptos morales puesto que tienen su fundamento en Dios, con lo que Bonet cierra el círculo entre lo religioso y lo moral: la causa última -y primera- de ambos es divina, esto es, radica en Dios, que es el primer motor de la moral e, igualmente, la causa final.

Este mismo argumento lo encontramos -casi veinte años después- en la conferencia que impartió en 1946, en Pamplona, sobre «Los católicos y el progreso moral». En esta ocasión -después del desastre de la Segunda Guerra Mundial, cuando todo el mundo se cuestionaba sobre si la sociedad avanzaba moralmente al mismo ritmo que técnicamente- manifestaba lo siguiente:

Observemos que el progreso moral es debido especialmente al principio de fecundación de los valores morales que es la religión. El problema moral no puede considerarse al margen del problema religioso. Sólo en personas muy contadas puede existir un sistema moral al margen de la religión. Para la generalidad de las gentes la vida moral tiene sus raíces en la vida religiosa, y cuando la fe religiosa se desvanece se cae con frecuencia en el amoralismo ${ }^{32}$.

32 Bonet, Alberto: El ideal social católico, Madrid, Acción Católica Española, I95I, p. 268. 
ALBERTO BONET Y SU ESTUDIO SOBRE LA CONCIENCIA MORAL DEL NIÑO (I927): A PROPÓSITO DE LOS PRIMEROS TRABAJOS SOBRE LA EDUCACIÓN MORAL ... MONSERRAT PAYÁ SÁNCHEZ Y CONRAD VILANOU TORRANO

Siendo, pues, la doctrina y el fin católicos los que engloban el instinto y el ideal moral, la formación de la conciencia moral dependerá de la religión -católica-, puesto que ésta es la que da sentido a una supuesta moral laica, social o ciudadana sobre la que nuestro autor no se muestra muy convencido pues, sin el espíritu de lo religioso, perdería esencia y sentido, contenido y «telos». La religión lleva a la moral a toda persona, con independencia de sus capacidades: está al servicio del género humano. La experiencia de conexión con Dios es la más plena y la que vivifica a la persona: de ahí su optimismo moral y religioso. Y sin moral -recordemos que para nuestro autor se fundamenta en la religión- se es menos humano ${ }^{33}$. Por su parte, la práctica religiosa confiere unidad al sujeto -conciencia y acción, también sentimiento-y le fortalece ante situaciones vitales difíciles que haya de afrontar. Sin embargo, el libro está dirigido, como reza su título, a la formación de la conciencia moral del niño y sólo el último capítulo, XII, aborda el tema de la formación de la conciencia religiosa -aunque se encuentren por el camino capítulos cuyo contenido está más cercano a la moral católica de la época: placer, castidad...-. La razón cabe hallarla en que Bonet concibe la educación religiosa y la moral en íntima relación: «Repitamos que la educación moral y religiosa son solidarias: sin una educación religiosa seria y profunda la educación moral carece de base sólida; sin ir acompañada de la educación moral, tampoco la religiosa se sostiene» ${ }^{34}$.

Seguidamente vamos a acompañar a nuestro autor en este recorrido natural por la formación de la conciencia moral-religiosa en el niño, deteniéndonos en resaltar aquellos elementos más innovadores y adelantados en su momento.

\subsection{La formación de la conciencia moral}

Bonet, además de clérigo ilustrado, debió ser un hombre de notables dotes de observación y elevada sensibilidad psicológica. En la obra insta a observar a los niños en todas las circunstancias del día a día: hay que prestar atención al juego, pero, más aún, a quienes no juegan. Junto con este medio, propone también la conversación dirigida a la escucha: dejar hablar y escuchar, sin censurar ni corregir, sino manifestando afecto y comprensión. Para conocer al niño y poder educarlo mejor. Una parte del pensamiento y la práctica de Rogers son manifiestas en este enfoque, aunque Bonet, también al lado del «otro», se sitúa como un compañero-guía en esta relación educativa que, por edad, es asimétrica: desde la confianza en el educando, en su buena voluntad y en el respeto hacia su educador. Consecuentemente, la misión del educador será la de entrar, con esa actitud, en comunicación con los niños, tanto individualmente como en grupo: entender su

33 Nótese la similitud con el pensamiento del profesor José Luis López Aranguren en su Ética (Madrid, Revista de Occidente, 1965) al afirmar que la experiencia moral y axiológica es la que nos humaniza.

34 Bonet, Alberto: La conciencia moral del niño: estudios teórico-prácticos acerca de su contenido y de su formación, op. cit., p. 215 . 
ALBERTO BONET Y SU ESTUDIO SOBRE LA CONCIENCIA MORAL DEL NIÑO (I927): A PROPÓSITO DE LOS PRIMEROS TRABAJOS SOBRE LA EDUCACIÓN MORAL ... MONSERRAT PAYÁ SÁNCHEZ Y CONRAD VILANOU TORRANO

lenguaje, conocer o intuir su espíritu -o su naturaleza-. Precisa, también, que la espontaneidad es compatible con la disciplina. Bonet dedica espacios en el libro a la formación de los educadores, de modo especial los escolares y religiosos, pero también incluye orientaciones para la familia y, en definitiva, todos cuantos estén en contacto continuado con el niño, porque son modelos y, en ello, pueden ser buen o mal ejemplo: la diferencia entre vivir moralmente o no.

La formación de la conciencia moral se inicia en el ámbito afectivo, junto con los instintos. La primera labor es la formación de los sentimientos morales que se encuentran ya, en estado embrionario, en el ser humano al nacer, por lo que se ha de preparar y cuidar el ambiente afectivo con el que se recibe al niño y en el que se desarrollará. Con este planteamiento, nuestro autor retoma el pensamiento de Pestalozzi, quien también daba central importancia a la formación de sentimientos morales y los situaba, en su origen, en la relación del recién nacido con la madre, como también hace Bonet. Continúa, igualmente, el pensamiento de san Agustín, quien defendía que se llega al alma por el sentimiento. En este abanico de posibilidades Bonet no olvida, con gran intuición, la formación de los sentimientos estéticos y critica, ya en su época, que no se tenga en cuenta que la educación estética es un factor indirecto o coadyuvante de la educación moral ${ }^{35}$. Por su parte, la educación religiosa además de influir sobre el sentimiento, lo hace sobre la calidad del sentimiento.

Plantea también la relación entre inteligencia y moralidad: la primera, de forma independiente, no asegura la presencia de moralidad: «La moral no es hija de la inteligencia» ${ }^{36}$. Aquí encontramos una de las más notables intuiciones de este autor, casi medio siglo antes de que Kohlberg la demostrara con su teoría psicológica del desarrollo del juicio moral ${ }^{37}$. Sin embargo, Bonet no se detiene ahí y prosigue afirmando que la inteligencia necesita del sentimiento y de la voluntad, otra gran intuición de nuestro autor que recoge dos de los puntos de crítica a la teoría de Kohlberg más importantes: el exceso de formalismo y el reducido papel de la cuestión afectiva sobre el razonamiento moral, por una parte, y que éste no asegure, por sí solo, el pase a la acción consecuente. Además, según nuestro autor, la formación moral facilita el desarrollo intelectual, afirmación que no ha sido investigada psicológicamente, desde la información de que disponemos, aunque, de manera indirecta, podemos apoyarnos para corroborarla en los estudios sobre

35 La educación estética ha sido la gran olvidada de la Pedagogía hasta hace relativamente poco tiempo. En este sentido es importante destacar las contribuciones al respecto de seminarios, grupos de investigación y revistas especializadas que, sin embargo, necesitan aún de mayor reconocimiento, p. e., en lo que se refiere a los planes de estudio de Pedagogía y grados afines. Sin embargo, conviene destacar el número monográfico -coordinado por el profesor Ángel C. Moreu- sobre «La estética, entre la historia y la pedagogía», Historia de la Educación. Revista Interuniversitaria, núm. 32 (2013). Entre los diversos artículos del monográfico, destacamos - para el tema que nos ocupa- el de RoviRó Alemany, Ignasi: «Los 50 primeros manuales de estética en España», pp. 47-79.

36 BONET, Alberto: La conciencia moral del niño: estudios teórico-prácticos acerca de su contenido y de su formación, op. cit., p. I8.

37 Kohlberg, Lawrence: Psicología del desarrollo moral, Bilbao, Desclée de Brouwer, 1992 [E] original data de 1984]. 
ALBERTO BONET Y SU ESTUDIO SOBRE LA CONCIENCIA MORAL DEL NIÑO (I927): A PROPÓSITO DE LOS PRIMEROS TRABAJOS SOBRE LA EDUCACIÓN MORAL ... MONSERRAT PAYÁ SÁNCHEZ Y CONRAD VILANOU TORRANO

educación emocional. Si bien educación moral y educación emocional no son sinónimas, sí que comparten aspectos afines: la dimensión afectuosa es un componente fundamental de la educación moral y de la adquisición de valores. Podemos añadir que las aportaciones de la educación libre -Neill, Wild-38 confirman la influencia positiva del bienestar afectivo sobre las adquisiciones intelectuales.

Otra notable intuición de Bonet, ligada al paradigma de educación moral como desarrollo del razonamiento moral, la hallamos cuando reflexiona en torno a lo que él expresa como «conciencias sobrepuestas» (véase cap. viII) y que muestra la delicada relación entre pensamiento y conducta moral. Con la anterior expresión se refiere al cambio de dirección moral de los niños cuando, tras dejar la escuela, se incorporan al mundo adulto, reflexionando sobre la insuficiencia e incluso fracaso de la acción educativa escolar. Lo hace desde una concepción más bien pesimista que no negativa, no de la infancia en particular, sino de la naturaleza humana en general. También desde un dualismo dicotómico, cercano al de Freud: el thánatos continúa activo y en desarrollo mientras la formación humana -cultural, social, moral- sigue su curso. Si ésta no ha calado hondo, fuera del ambiente habitual del niño, las primeras fuerzas emergen anulando las segundas. Si a ello se le suma la capacidad de adaptación de la persona -al nuevo ambiente y códigos morales-, el cambio de dirección y, con él, el fracaso educativo está asegurado.

Bonet no sólo constata y reflexiona sobre las causas, también ofrece alternativas y, para superar este riesgo, propone educar más que instruir; alargar la edad de escolarización -mostrando su preocupación por las clases económicamente débiles que no pueden costear estudios postescolares-; y realizar una acción educativa significativa y en profundidad. Sobre este particular, realiza una crítica perfectamente transferible al momento actual: «La escuela moderna busca más la extensión que la profundidad, no sólo en materia de instrucción, sino también en el terreno de la educación. Multa, non multum, parece ser su divisa. Con todo, el trabajo en profundidad es lo que interesa»39. Que la acción educativa se realice con profundidad y sea comprendida -y, entonces, valorada- por el niño, conducirá a que se moldee su carácter y personalidad. Bonet no se queda, pues, en la superficie de los contenidos ni se contenta con alcanzar pequeños objetivos: tiene puesta la mira en la formación ética total de cada niño. Sin ignorar la complejidad de tal cometido, se compromete por entero con él: su intención es llegar al alma de cada niño para que enfoque su vida desde el sentido ético de la misma y lo haga de forma holística.

En último lugar, el autor de La conciencia moral del niño se interroga sobre la influencia de la instrucción en el desarrollo de la conciencia moral. Si bien le concede un papel secundario, considera que la educación moral, acompañada de la adquisición de contenidos culturales, amplía el desarrollo moral. En esta reflexión

${ }_{38}$ NeILL, Alexander Sutherland: Corazones, no sólo cabezas en las escuelas, México, EMU, 1975; WILD, Rebeca: Calidad de vida: Educación y respeto por el crecimiento interior de niños y adolescentes, Barcelona, Herder, 2003.

39 BONET, Alberto: La conciencia moral del niño: estudios teórico-prácticos acerca de su contenido y de su formación, op. cit., p. 98. 
ALBERTO BONET Y SU ESTUDIO SOBRE LA CONCIENCIA MORAL DEL NIÑO (I927): A PROPÓSITO DE LOS PRIMEROS TRABAJOS SOBRE LA EDUCACIÓN MORAL ... MONSERRAT PAYÁ SÁNCHEZ Y CONRAD VILANOU TORRANO

podemos hallar la conexión con planteamientos actuales de educación en valores que explicitan como una de las vías de desarrollo moral la adquisición de contenidos culturales y sociales establecidos en sociedades democráticas y plurales ${ }^{40}$.

A lo largo de toda la obra, Bonet se posiciona en contra del verbalismo como procedimiento para la adquisición de aprendizajes de cualquier tipo. Él apunta hacia el aprendizaje comprensivo y unitario en todos los ámbitos, también en el que nos ocupa. Comprender la necesidad de tal o cual precepto-que conducirá a la estima-; organizar los conocimientos y establecer relaciones entre ellos -que permiten una comprensión en profundidad, así como anticipar las consecuencias de una forma de proceder en concreto-; y llegar a configurar una visión holística de la realidad -conciencia plena y responsabilidad; sentimientos, intelecto y conducta.

\subsection{La adquisición de bábitos como procedimiento para la formación de la conciencia moral}

Ni que decir tiene que la propuesta educativa de mosén Bonet responde a un modelo de clara orientación teleológica - por establecer el contenido de la educación moral a partir de la religión católica- aunque está atravesado por interesantes incursiones de aportaciones de otros paradigmas actuales: el cognitivo o de desarrollo del razonamiento moral (Piaget, Kohlberg) y el de construcción de la personalidad moral (Puig, Martínez) ${ }^{4+}$. Muestras de ello han sido esbozadas anteriormente -relación entre desarrollo moral y desarrollo cognitivo; aprendizaje unitario u holístico-. En este apartado vamos a concretar sus aportaciones más importantes y a situarlas en estos enfoques.

De acuerdo con su filosofía de la educación conformada según los principios de la pedagogía perenne, que se caracteriza por la dimensión teleológica, Bonet concede una gran importancia al desarrollo de hábitos morales. Conocedor de la clásica obra La educación moral (1903) de Émile Durkheim -a quien podríamos situar dentro de este mismo modelo por definir claramente el contenido de la educación moral, la socialización y, con ella, la culturización- $-^{42}$, Bonet otorga un lugar prioritario a la formación de hábitos morales, base de la educación moral y que debe iniciarse desde la infancia. Junto a ella, se plantea también la finalidad de preservar al niño de hábitos inmorales o de extraerlos, si ya han arraigado.

El medio para desarrollar los hábitos morales será la obediencia consciente y voluntaria. Y una obediencia de tales características sólo puede nacer del sentimiento, si no se quiere hacer de ella una imposición. En este momento es cuando

40 Puig Rovira, Josep Maria: La construcción de la personalidad moral, Barcelona, Paidós, 1996; Martínez, Miguel: El contrato moral del profesorado. Condiciones para una nueva escuela, Bilbao, Desclée de Brouwer, 1998.

${ }_{41}$ Piaget, Jean: El criterio moral en el niño, Barcelona, Fontanella, 1983 [El original data de I932]; Kohlberg, Lawrence: Psicología del desarrollo moral, Bilbao, Desclée de Brouwer, 1992 [El original data de 1984]; PUIG Rovira, Josep Maria: La construcción de la personalidad moral, op. cit.; Martínez, Miguel: El contrato moral del profesorado. Condiciones para una nueva escuela, op. cit.

42 Durkheim, Émile: La educación moral, Madrid, Trotta, 2002. 
ALBERTO BONET Y SU ESTUDIO SOBRE LA CONCIENCIA MORAL DEL NIÑO (I927): A PROPÓSITO DE LOS PRIMEROS TRABAJOS SOBRE LA EDUCACIÓN MORAL ... MONSERRAT PAYÁ SÁNCHEZ Y CONRAD VILANOU TORRANO

Bonet se acerca de nuevo a las aportaciones de Pestalozzi, Cómo Gertrudis educa a sus hijos (I80I): en la relación afectiva entre la madre e hijo, se desarrollan sentimientos que después serán la base de virtudes sociales, como las de obediencia y gratitud $^{43}$. Son muchos los párrafos que Bonet dedica a establecer la importancia del primer ambiente afectivo de los niños, sabedor de su importancia para un buen desarrollo moral. Se advierte también en este planteamiento cómo Bonet incluye el nada fácil tema de la libertad. En el desarrollo moral se encuentra la alianza entre obediencia y libertad: hacer libremente, voluntariamente, lo que se debe hacer. Porque si, para Bonet, la noción de deber es uno de los fundamentos de la educación moral, no lo concibe desde la imposición externa y heterónoma, sino desde la propia voluntad, el querer autónomo y, en ese sentido, libre. Si se deja al niño la posibilidad de autorregularse, si se le permite la espontaneidad y la toma de iniciativa - «cierta» iniciativa, indica Bonet-, se favorecerá su maduración y su autonomía. Mediante esas prácticas se conseguirá formar el hábito de autodeterminación. Y ese hábito, a su vez, es el camino hacia la responsabilidad.

Coherentemente con esta visión, Bonet otorga un papel relevante, ya lo hemos comentado, a los educadores, porque en su tarea docente y en su ejemplo se juega gran parte del éxito del aprendizaje de hábitos morales. De entre todas las consideraciones que hace al respecto, queremos destacar la de ser fuente de autoridad, otra de las bases de la educación moral. La autoridad a la que alude nuestro autor es, nuevamente, una autoridad que nace del afecto, no impositiva ni coercitiva. Por eso muchas veces la expresa como sentimiento de autoridad. Es tarea del educador ganarse o hacerse digno de esa autoridad respecto al niño, lo que conseguirá siendo cercano y sensible a los intereses y necesidades de sus alumnos; siendo prudente, no anticipando juicios y obrando justamente; adaptando todas las acciones al modo de ser específico de cada niño y siendo un ejemplo para ellos.

Vemos, pues, cómo para Bonet autoridad es, en cierto modo, sinónimo de respeto: el respeto debido a quien procede de manera moral, a quien es una persona moral o ética. Pero también puede suponer una influencia antieducativa cuando el educador no procede correctamente, siendo indigno de su nombre ${ }^{44}$ : educadores que buscan la adulación, provocando actos de hipocresía en los niños; que ahogan con un exceso de normativa, facilitando las transgresiones a la misma; los violentos, que no escuchan y provocan temor; los orgullosos, que no rectifican ni reconocen al otro.

De forma natural, Bonet aborda también el tema de los castigos, en cuyo desarrollo encontramos puntos de semejanza con el sistema preventivo de san Juan Bosco recomendando ambos el evitar la ocasión ${ }^{45}$. Se define partidario del castigo, pero utilizándolo «lo menos posible» puesto que «no liga al alma» $\mathrm{y}$ «disminuye

43 Pestalozzi, Johann Heinrich: Com Gertrudis educa els fills, Vic, Eumo, 1986.

44 Bonet, Alberto: La conciencia moral del niño: estudios teórico-prácticos acerca de su contenido y de su formación, op. cit., p. 93.

45 SAN Juan Bosco: «El sistema preventivo en la educación de la juventud», en Normas pedagógicas en uso en los colegios salesianos y Didáctica particular para la primera enseñanza, Barcelona, Escuelas Profesionales Salesianas, 1943, pp. 9-18 [El original data de I877]. 
ALBERTO BONET Y SU ESTUDIO SOBRE LA CONCIENCIA MORAL DEL NIÑO (I927): A PROPÓSITO DE LOS PRIMEROS TRABAJOS SOBRE LA EDUCACIÓN MORAL ... MONSERRAT PAYÁ SÁNCHEZ Y CONRAD VILANOU TORRANO

su dignidad humana y embota su sensibilidad moral» - la de los discípulos- ${ }^{46}$. San Juan Bosco - que tanta influencia ha tenido sobre la ciudad de Barcelona, donde la presencia salesiana se remonta a fines del siglo XIX- decía: "Cuando sea posible, no se castigue nunca». Ambos autores rechazan, pues, castigos humillantes o hirientes, como el uso de la ironía. También abogan por que se hagan en privado. Sólo las faltas colectivas merecen un castigo colectivo, el que nunca deberá utilizarse para faltas cometidas por unos pocos niños. Bonet aconseja que, juntamente con el anuncio del castigo, se exprese también la confianza en la enmienda del niño y que se destaquen algunas de sus cualidades.

Se observa aquí la importancia del afecto y la comunicación para nuestro autor, su interés por que el vínculo creado con el niño no se rompa y se preserve la relación educativa. Así, por ejemplo, aconseja que medie un espacio de tiempo suficiente entre la falta y el castigo para que éste no se pueda confundir con la ira o la rabia. Los castigos han de ser justos: «Un castigo injusto es inmoral» ${ }^{47}$ y atacaría de pleno el objetivo que se desea alcanzar. Lo que se pretende con un castigo es hacer volver el respeto a la norma: si un castigo no lo consigue, entonces no es un buen castigo y no debería ser aplicado nunca. El educador, además, ha de saber distinguir entre faltas de disciplina, travesuras y faltas morales, que son las que deben corregirse enseguida y firmemente. Ante las primeras, aconseja manifestar extrañeza acompañada de los sentimientos de dolor y tristeza. Respecto a las segundas, dirigirse a la inteligencia y al corazón del niño, explicando las consecuencias de la conducta, también las afectivas. La reparación es lo que ha de permitir el castigo: ante una falta de orgullo, aumentar la humildad; ante una de falsedad, recurrir a la confesión. El análisis de la falta, junto con la toma de conciencia de sus consecuencias, el reflexionar junto al niño es lo que permitirá el cambio y hará encontrar el sentido del castigo. Es en esta opción por procedimientos reflexivos y de autoconocimiento que encontramos ciertas semejanzas con el paradigma de educación moral como construcción de la personalidad moral. También observamos que, aunque ubicado en el paradigma de la pedagogía tradicional, sobresale el sentido humanista que entronca con la pedagogía perenne, con su base metafísica y su perspectiva teleológica.

Quizá porque el catolicismo concede un lugar especial al pecado y al sentimiento de culpa, Bonet dedica algunas páginas a reflexionar sobre el valor pedagógico del dolor, que es aliviado por la piedad, y reconoce el valor moral de niños y adolescentes gravemente enfermos que así lo enfrentan. Se podría decir que el ascetismo está también entre las vías propuestas por Bonet para educar moralmente, una forma de vida ascética adecuada a la naturaleza del niño -renunciar voluntariamente a ciertas gratificaciones, esforzarse por realizar acciones contrarias a la propia naturaleza para desarrollar una virtud, asumir los contratiempos sin quejarse-. El esfuerzo es también un medio para llegar a la virtud, no sólo individualmente sino colectivamente porque lleva a la resistencia y voluntad

46 Bonet, Alberto: La conciencia moral del niño: estudios teórico-prácticos acerca de su contenido y de su formación, op. cit., p. 72.

47 Ibidem, p. 73 . 
ALBERTO BONET Y SU ESTUDIO SOBRE LA CONCIENCIA MORAL DEL NIÑO (I927): A PROPÓSITO DE LOS PRIMEROS TRABAJOS SOBRE LA EDUCACIÓN MORAL ... MONSERRAT PAYÁ SÁNCHEZ Y CONRAD VILANOU TORRANO

de superación, sin las cuales «[...] no es posible ninguna lucha, ni intelectual, ni social, ni económica ni política; menos aún moral. Y si no es posible la lucha, mucho menos lo es la victoria» ${ }^{4}$. Bien se comprende que años después, en una conferencia dictada el año I946, sobre los católicos y el progreso moral ya comentada más arriba, insistiese sobre el particular: «Por eso hay que educar a los pequeños a vencerse y renunciar a lo ilícito, a gustos pequeños, para que después sepan vencerse en las grandes luchas y renunciar a lo ilícito en las grandes tentaciones, que no han de faltar porque no faltan nunca a nadie»49.

Poner en contacto a los niños con el arte y la historia, abriendo la reflexión sobre el esfuerzo, constancia, sacrificio -y también, dolor-, que supusieron ciertos monumentos o eventos históricos y que narran ciertas pinturas, y relacionándolos con la fe cristiana, es educativo y un medio de preparación para la vida adulta -toma de conciencia, valoración, implicación social y política-. De lo anterior se desprende que valora la emulación como medio educativo, también en el ámbito moral. Plantea recurrir a la vida de los animales como modelo pedagógico, por los valores de constancia, esfuerzo, fidelidad... que muestran y se sorprende de que en Pedagogía se haya utilizado profusamente el símil de las plantas y no el de los animales. Nuevamente nuestro autor no se contenta con una emulación simple, puntual, que se queda en la reacción impulsiva y que, o bien sólo retiene las grandes gestas o los actos heroicos de la humanidad, o se queda en la superficie y las formas, sino que busca una imitación de lo que subyace a esos ejemplos y modelos: una emulación de lo esencial. Resulta interesante la alternativa que ofrece a fin de conseguir tales propósitos: la creación de una asignatura que, sin embargo, supera la separación entre materias, al recoger las aportaciones en este sentido del resto de las asignaturas y presentarlas de manera integrada mediante el diálogo conjunto profesor-alumnos. Asignatura que considera necesaria en Primaria, Secundaria y Universidad también, que llevaría a ser tema de conservación espontánea entre los niños y se extendería hasta las familias. Imagina también que tuviera su lugar en diferentes espacios de la vida social, de lo que se desprende que la concibe también como educación informal y que ésta, la educación, puede darse en cualquier espacio y a lo largo de la vida.

Emulación e idealismo van asociados. Recordemos que hemos destacado como principios pedagógicos de Bonet los de realismo e idealismo en equilibrio, aunque dedique un capítulo, el x, al idealismo infantil. Considera que la naturaleza del niño le lleva a querer y buscar lo que le habla de heroísmo, misticismo, ensueños y misterios ${ }^{50}$. Por tanto, es ésa una tendencia que se ha de procurar conservar y utilizarla como elemento de motivación, aspecto que va parejo a su curiosidad por conocer y saber, para lo que cita El Criterio de Balmes, obra escrita en i843 y publicada dos años después, y que se actualizó en I9ıo, cuando se cumplió el primer centenario del nacimiento del pensador vicense.

$4^{8} \quad$ Ibidem, p. 86.

49 Bonet, Alberto: El ideal social católico, op. cit., p. 274.

so BONET, Alberto: La conciencia moral del niño: estudios teórico-prácticos acerca de su contenido y de su formación, op. cit., p. I07. 
ALBERTO BONET Y SU ESTUDIO SOBRE LA CONCIENCIA MORAL DEL NIÑO (I927): A PROPÓSITO DE LOS PRIMEROS TRABAJOS SOBRE LA EDUCACIÓN MORAL ... MONSERRAT PAYÁ SÁNCHEZ Y CONRAD VILANOU TORRANO

A tenor de lo expuesto, todo hace suponer que Balmes -aferrado a un realismo gnoseológico- fue una especie de maestro-pensador para la generación de Alberto Bonet no sólo en los años de juventud, sino también en la madurez, tal como lo atestiguan la gran cantidad de estudios y trabajos publicados en la década de los cuarenta y cincuenta ${ }^{5 \mathrm{I}}$. Acaso por esto, la doctrina social de la Iglesia encuentra un claro precedente en el pensamiento de Jaime Balmes, tal como se desprende de la siguiente afirmación de Bonet:

El ideal social católico es, en suma, el ideal de la dignidad y de la fraternidad humana; es el de la elevación integral del linaje; es, por decirlo con la famosa expresión de Balmes, el que reclama el mayor bien posible -moral, intelectual y económicopara el mayor número posible ${ }^{s^{2}}$.

No deja lugar a dudas que su ideario depende de Balmes, así como del obispo Torras y Bages, del filósofo Francisco J. Llorens Barba y del literato Manuel Milá y Fontanals. Los tres últimos constituyen los bastiones de lo que Bonet denomina la escuela «vilafranquesa», por proceder los tres autores -Torras, Llorens y Milá- de Vilafranca del Penedés ${ }^{53}$. Como se ve, a su modo, Alberto Bonet también defiende la existencia de una escuela filosófica con clara orientación religiosa que incluye el pensamiento de Llorens Barba.

En cualquier caso, el papel del educador es ofrecer experiencias variadas a los niños para despertar tanto intereses, como capacidades específicas y, quizá, aún no sospechadas. Expresa la finalidad de esta práctica muy bellamente: no es la de formar soñadores en las nubes, sino la de «saturarlos de idealismo para que mejor dominen la realidad [...]. Queremos acercar la vida al ideal, tanto como sea posible» ${ }^{4}$. Bonet comparte, pues, con Mantovani (1933) y la corriente idealista que el fin de la educación es conseguir el máximo desarrollo, armónico también, de las facultades humanas, sin descuidar, por ello, la dimensión social. De ahí también la presencia constante en el pensamiento de Bonet de los diferentes agentes e instancias sociales que, con su influencia, pueden operar para conseguir o entorpecer la consecución de tal fin.

st Bonet, Alberto: «Cómo veía Balmes el proceso industrial y la reacción de las clases obreras en Cataluña», Revista Internacional de Sociología, núm. 22-23 (1948), pp. 233-283. Este artículo también se incluyó en el libro de BonET: El ideal social católico, op. cit., pp. 123-202.

52 Bonet, Alberto: El ideal social católico, op. cit., p. 27.

53 El obispo José Torras y Bages perfiló diversos recuerdos y semblanzas de Francisco J. Llorens Barba, de quien ensalza dos virtudes por encima de todo: su carácter religioso y su humildad filosófica. Desde un punto de vista filosófico, lo presenta como un especialista de la observación interna, si bien nunca se olvidó del mundo externo. «Fou en Llorens principalment un psicòleg, un home d'observació interna, que vivia perennement en la cel·la de la pròpia consciència, que llegia amb admirable facilitat les manifestacions humanes dins de l'horitzó de la consciència íntima, com en un llibre misteriós ple d'insinuacions lluminoses, i amb fruïció repetia aquella sentència, de que els dos espectacles de major magnificència que l'home pot contemplar són la volta del cel estrellada i la pròpia consciència moral» (Torras I BAGEs, Josep: Obras Completes, vol. III, Barcelona, Publicacions de l'Abadia de Montserrat, 1987, p. 558).

${ }^{4}$ BONET, Alberto: La conciencia moral del niño: estudios teórico-prácticos acerca de su contenido y de su formación, op. cit., pp. IIo-III. 
ALBERTO BONET Y SU ESTUDIO SOBRE LA CONCIENCIA MORAL DEL NIÑO (I927): A PROPÓSITO DE LOS PRIMEROS TRABAJOS SOBRE LA EDUCACIÓN MORAL ... MONSERRAT PAYÁ SÁNCHEZ Y CONRAD VILANOU TORRANO

En este complejo equilibrio entre realismo e idealismo, podemos situar la sinceridad como una cualidad de los educadores a la vez que un indispensable medio para la formación moral de los niños. En todos los temas, se ha de ajustar la explicación a la capacidad cognitiva del niño. El silencio, especialmente de los padres, es contraproducente, pues genera grandes daños además de poner en peligro la confianza entre sus hijos y ellos. Bonet nos recuerda que «La inocencia no es la ignorancia. La conciencia moral necesita apoyarse en tierra firme; no en el barro de la mentira o en el vacío del silencio, sino en la roca viva de la verdad» $"$. Además, evitar o posponer largamente las respuestas a las preguntas naturales del niño puede conducir a que busque esas respuestas en otros agentes, quienes, a su vez, pueden estar mal informados o proporcionar la verdad prematuramente, cuando el niño aún no está preparado para comprenderla. Las explicaciones deben proporcionarse de forma progresiva y presentarse como prueba de confianza y de afecto. De este modo, la relación entre padres e hijos o educadores y alumnos se asentará «en tierra firme», se hará sólida y duradera.

Por último, la capacidad de introspección es otra vía de educación moral que debe ir en consonancia con el desarrollo evolutivo. Conviene también fijarse en aquellos niños que la tienen más desarrollada porque Bonet parece temer más por su exceso que por su defecto, ya que podría producir en la conciencia «una especie de asfixia moral» $\$$. Para superar este riesgo, propone reconocer los méritos del niño y hacerle notar la importancia y necesidad de que el autoanálisis se realice con medida y equilibradamente. El exceso podría conducir a desarrollar personalidades temerosas, incapaces de actuar por miedo a errar, o bien, a abandonar el objetivo y ceder a las pasiones, peligro éste que considera mayor.

\subsection{Religión y educación: la formación de la conciencia religiosa}

No quedaría completo este análisis si no dedicáramos un espacio a la educación religiosa. Con ella concluye Bonet la obra estudiada y consideramos significativo que la inicie con la formación de la conciencia moral para llegar a la de la conciencia religiosa. De este modo, entendemos, Bonet no se contradice. Su «telos» estaba muy bien definido desde el principio, la fe católica. Aunque lo religioso incluya y supere lo moral y lo moral necesite de lo religioso para ser más pleno, dado que ambas esferas están tan íntimamente relacionadas y para desarrollarlas se ha de partir de la experiencia y del sentimiento, la formación de la conciencia moral y de la conciencia religiosa, como ya indicamos al principio de este apartado, se realizan simultáneamente. De lo social, la conciencia moral tiene pronto abundantes situaciones de experiencia; el sentido y la orientación serán marcados por el telos católico.

En el fondo, en el universo de Bonet, la obediencia a Dios da fuerza y sentido a todos los preceptos morales. Aunque evolutivamente se presente primero la

"Ibidem, p. 157 .

56 Ibidem, p. 90. 
ALBERTO BONET Y SU ESTUDIO SOBRE LA CONCIENCIA MORAL DEL NIÑO (I927): A PROPÓSITO DE LOS PRIMEROS TRABAJOS SOBRE LA EDUCACIÓN MORAL ... MONSERRAT PAYÁ SÁNCHEZ Y CONRAD VILANOU TORRANO

obediencia a los padres, enseguida se funde con la obediencia a Dios. Produce cierta extrañeza que Bonet no aluda expresamente a los sentimientos en el seguimiento de este principio, aunque se intuya su inclusión, como sí había hecho en relación a la formación de la conciencia moral. También extraña que no trate el amor a Dios, aunque antes de morir -y en medio del ambiente postconciliar- dedicó una monografía a esta cuestión de la que puede derivarse una pedagogía del amor, fruto de la revolución cristiana del amor universal de raíz franciscana ${ }^{57}$. Es posible que este olvido se deba a que Bonet está muy centrado en la obediencia como la principal fuerza de cambio en la estructura de la personalidad y por su énfasis en la adquisición de hábitos. Como fundamento, se apoya en Claparède, quien le confirió la misma fuerza aun en el supuesto de que la religión no fuera verdadera. Ello parece indicar que la fuerza de la obediencia es, en realidad, la fuerza de la creencia, y puede ser interesante destacar que éstas, las creencias, poseen una fuerte carga afectiva. Tras exponer y examinar rigurosamente todos los argumentos y contraargumentos a este planteamiento, nuestro autor concluye lo siguiente:

La religión objetivamente verdadera será la pedagógicamente más eficaz. Pero también es legítima la inferencia inversa, a saber, que la religión pedagógicamente más eficaz sea también la objetivamente verdadera. «Por los frutos los conoceréis», ha dicho el divino Maestro ${ }^{58}$.

En función de sus principios pedagógicos, establece la diferencia entre instrucción y educación religiosas: la primera es necesaria, pero no suficiente. Es la base, pero no el alma ni el motor de la vida según la fe. Reivindica el lugar de la educación religiosa en la escuela, en Primaria y en Secundaria y no sólo en el ámbito familiar. Se plantea también la cuestión de la neutralidad en este ámbito, arguyendo que, además de ser prácticamente imposible, la neutralidad no es deseable, al menos en esta cuestión, porque, como ya había indicado en relación a otros temas, como el de la sexualidad, el silencio ante ciertas preguntas no es pedagógico.

Respecto a cuándo iniciarla, se posiciona al lado de Herbart, en la infancia, y en contra de Kant y Rousseau -en la adultez y la juventud, respectivamente-. Se ha de iniciar también desde el nacimiento porque, de acuerdo con su planteamiento, recordemos, la educación religiosa es la base de la educación moral e, impartida al inicio de la vida, arraiga naturalmente en la conciencia. Ahí se muestra la importancia de la formación de la conciencia moral de la que mosén Bonet fue un adelantado. Para él, el niño posee también un sentimiento religioso innato -habla de «religiosidad nativa» en el niño-59, de su capacidad para llegar a la idea de Dios en su sentido filosófico, relacionada con la de causa primera en Aristóteles, además de que la religión ayuda y no se puede negar a nadie ese apoyo.

57 Bonet, Alberto: La llei de l'amor universal, Barcelona, Nova Terra, 1973.

${ }_{58}$ Bonet, Alberto: La conciencia moral del niño: estudios teórico-prácticos acerca de su contenido y de su formación, op. cit., p. 190.

59 Ibidem, p. 194. 
ALBERTO BONET Y SU ESTUDIO SOBRE LA CONCIENCIA MORAL DEL NIÑO (I927): A PROPÓSITO DE LOS PRIMEROS TRABAJOS SOBRE LA EDUCACIÓN MORAL ... MONSERRAT PAYÁ SÁNCHEZ Y CONRAD VILANOU TORRANO

A continuación desgrana un conjunto de orientaciones que no nos resistimos a ofrecer por la exquisita coherencia con todo su planteamiento. El profesor de religión ha de tener autoridad moral y capacidad de comunicación. Del mismo modo que una persona no creyente no puede ser profesora de religión, tampoco basta con creer y tener bondad. Ha de saber despertar el interés en el alumnado, para lo que la Pedagogía y la práctica catequista suministran técnicas y métodos, aspectos que la pedagogía claretiana había desarrollado enormemente en el siglo XIX. Por ello reivindica también la formación de los seminaristas en Pedagogía catequista y alaba la iniciativa del entonces obispo de Barcelona, José Miralles, quien ya la incluyó como asignatura en el Seminario. Preciso es reconocer que José Miralles -obispo en la ciudad Condal entre 1926 y I930, cuando pasó a Palma de Mallorca- mantuvo siempre buenas relaciones con Alberto Bonet, a quien invitó en diversas ocasiones para difundir el ideario de la Federació de Joves Cristians -fundada por Bonet en I93I y actuando como consiliario general hasta 1936-, iniciativa que no cuajó en las Islas Baleares ${ }^{60}$.

No es menos cierto, tampoco, que las enseñanzas deben basarse en la verdad: no conviene falsear el contenido a transmitir ni utilizarlo con fines diferentes a la espiritualidad. Se pueden utilizar las parábolas y hechos bíblicos para fomentar el sentimiento y la espiritualidad. También imágenes y objetos de culto, pero sin olvidar que son simplemente apoyos puntuales. Al igual que en la formación de la conciencia moral, es necesario conocer previamente los intereses psicológicos del niño, también sus necesidades, preocupaciones y sueños, para enlazar con ellos la educación religiosa. Vemos en esto la vinculación con el paradigma cognitivo-evolutivo del desarrollo moral y los planteamientos activos y vitalistas desde Rousseau y toda la Escuela Nueva: une lo religioso con la vida. Incide también en el tono, que ha de ser familiar, cercano y alegre; que les haga de vez en cuando sonreír y de vez en cuando pensar seriamente. El diálogo es el procedimiento, porque permite conocer lo que interesa o preocupa al niño, así como el proceso de comprensión que sigue y la posible germinación de lo que se transmite. En consecuencia, la clase de religión debe prepararse con cuidado: con sistematización y secuenciando aprendizajes, ofreciendo ejemplos, mostrando la relación con el todo... Y en esto, como en toda la educación, menos es más: calidad antes que cantidad. Consciente también de la importancia del contenido memorístico, aconseja facilitarlo acompañándolo de ejemplos e ilustraciones y valerse del canto $^{61}$. El canto religioso tiene, además, el efecto de devenir medio de educación informal: llega a la familia, a los transeúntes... De lo anterior se desprende que aboga también por la formación del profesorado de religión, así como por la participación en estas clases de los sacerdotes de las parroquias, con lo que potencia la relación escuela y vida, escuela y sociedad.

60 González-Agàpito, Josep; Marquès, Salomó; Mayordomo, Alejandro y Sureda, Bernat: Tradició i renovació pedagògica. I898-1939. Història de l'educació. Catalunya, Illes Balears, País Valencià, Barcelona, Publicacions de l'Abadia de Montserrat, 2002, p. 634.

${ }_{61}$ Al valorar la decisión tomada en Italia en aquella época, que lo había implantado junto con la enseñanza del catecismo, Bonet muestra no sólo su actualizada revisión de la temática, sino también su interés y estima por ella. 
ALBERTO BONET Y SU ESTUDIO SOBRE LA CONCIENCIA MORAL DEL NIÑO (I927): A PROPÓSITO DE LOS PRIMEROS TRABAJOS SOBRE LA EDUCACIÓN MORAL ... MONSERRAT PAYÁ SÁNCHEZ Y CONRAD VILANOU TORRANO

La educación religiosa necesita de la experiencia para llegar a su objeto, la fe. Por ello, se deben ofrecer situaciones y prácticas que lleguen al sentimiento, y asegurar la repetición. Los agentes educativos son la familia, el sacerdote y el maestro, que educan sobre todo con el ejemplo constante y próximo, esto es, explicando y comunicando su sentimiento. Insta a los padres a realizar esta función, «su deber más riguroso y más grave» ${ }^{62}$. Además, concede en los primeros años, a la madre, un papel especial -incluso antes del nacimiento, como Pestalozzi-. Apoyándose en la carta pastoral de la cuaresma de I9I3 sobre la educación maternal del obispo José Torres y Bages -que como hemos visto mostró sus simpatías por la filosofía de Llorens Barba, con quien trabó una buena amistad hasta el punto de acompañarle espiritualmente en su agonía-, Bonet concede el primer lugar al amor filial entre la madre cristiana y su hijo ${ }^{63}$.

Como primer eslabón de la cadena, la devoción religiosa de la madre, de la que hace partícipe a su hijo, determina que el amor que les une sea todavía más fuerte y poderoso. No es sólo por amor, sino también por deber que la madre ha de cuidar la formación de la conciencia moral y religiosa de su hijo/a. En este marco, sin embargo, el amor ocupa un lugar especial porque es el mejor instrumento para la enseñanza de lo religioso y porque la religión existe por el amor, ideas ambas tomadas de Torras y Bages. El padre comparte el deber de la educación religiosa de su hijo/a y es insubstituible en esa labor, respetando así Bonet la igualdad de género. Ambos lo han de hacer desde la sinceridad y el ejemplo. La vida religiosa en familia, las prácticas religiosas y las asociaciones parroquiales son también excelentes vías. El sacerdote, por su parte, tiene la función de actuar como director espiritual y «director de conciencia» ${ }^{64}$. Al tratar la práctica del examen de conciencia, Bonet expresa su relación con los procesos de autoconocimiento, uno de los principales procedimientos de la personalidad moral y medio para llegar a la autonomía como ya hemos mencionado. Aunque se percibe cierto enfoque negativo de base -primero, destruir defectos, después, conseguir virtudes-, menciona la importancia de prácticas de autocontrol verbal y el ejercicio del comportamiento virtuoso que se desea alcanzar. Experiencias y prácticas siempre concretas y cercanas a la vida cotidiana del niño. Formación de hábitos, formación del carácter y amor.

En resumen, Albert Bonet construye un medio pedagógico, cuidado y rico, en el que el niño pueda desarrollar su conciencia moral y religiosa: un ambiente afectivo respetuoso con la personalidad del niño y que infunda confianza, y un entramado de situaciones de experiencia en las que el niño pueda ejercitar las conductas apropiadas de la fe católica y sentirse, al mismo tiempo, miembro activo de la comunidad. Y todo ello, a nuestro entender, en sintonía con la estela de la

${ }^{62}$ BoneT, Alberto: La conciencia moral del niño: estudios teórico-prácticos acerca de su contenido y de su formación, op. cit., p. 208.

${ }_{63}$ Torras i Bages, Josep: «L'educació maternal», en Obres Completes, vol. vi, Barcelona, Publicacions de l'Abadia de Montserrat, I989, pp. I27-I66.

${ }^{6}$ Bonet, Alberto: La conciencia moral del niño: estudios teórico-prácticos acerca de su contenido y de su formación, op. cit., p. 216. 
ALBERTO BONET Y SU ESTUDIO SOBRE LA CONCIENCIA MORAL DEL NIÑO (I927):

A PROPÓSITO DE LOS PRIMEROS TRABAJOS SOBRE LA EDUCACIÓN MORAL ... MONSERRAT PAYÁ SÁNCHEZ Y CONRAD VILANOU TORRANO

tradición filosófica catalana que remarca el papel de la conciencia particularmente en lo referente a la praxis moral o, mejor aún, a la educación moral.

\section{Alejandro Sanvisens, pedagogo de la conciencia}

Como venimos sosteniendo, la conciencia constituye un elemento fundamental de la escuela filosófica catalana con importantes implicaciones educativas. Presente en Ramón Martí de Eixalá y Francisco J. Llorens Barba, Tomás Carreras Artau dio validez a una corriente de pensamiento que posee una inequívoca vocación pedagógica. Lo acabamos de ver con el libro de mosén Bonet sobre la conciencia moral del niño, un trabajo pionero que sobre la base de la pedagogía perenne no desentona en absoluto si lo comparamos con otras aportaciones de la época y que pone de manifiesto la riqueza de las investigaciones que se forjaron al socaire del Seminario de Ética de la Universidad de Barcelona, dirigido por Tomás Carreras, de quien el profesor Sanvisens glosó sus cualidades y excelencias el año 1956. En efecto, en un trabajo mecanografiado de i8 páginas -hoy felizmente recuperado- ${ }^{65}$ Alejandro Sanvisens nos dejó un retrato personal e intelectual de su maestro, que sirvió de texto para dictar la conferencia pronunciada el I4 de diciembre 1956 en el Teatro de la Caja de Jubilaciones y Subsidios Textiles de Barcelona (Aragón, 275), a instancias de la Hermandad de San Narciso -patrón de Gerona- de Barcelona.

Por todo cuanto venimos diciendo, es obvio que el profesor Alejandro Sanvisens (I9I8-1995) era bien consciente de esta tradición pedagógica. De buen seguro que conocía, además, el libro Un viatge de cara als joves, de Alberto Bonet, aparecido en $1931^{66}$. Después de visitar diversas experiencias católicas de pedagogía juvenil en algunos países europeos, Bonet -en aquellos momentos profesor auxiliar de la Universidad de Barcelona- detectó que la escuela era algo insuficiente para contribuir a la formación moral de las personas. De ahí que estableciese la distinción entre pedagogía escolar y postescolar, ideas que llevó a la práctica a partir de I93I con la creación de la Federació de Joves Cristians de Catalunya, en cuya dirección contó con el apoyo del médico Pedro Tarrés, hoy beatificado. Lamentablemente, la historia de la Federació -un ejemplo moderno y renovador de pedagogía juvenil, inspirado entre otras fuentes en la Joc belga- acabó, como tantas otras cosas, en el mes de julio de 1936. Años después, finalizada la Guerra Civil, Bonet fue reclamado desde Madrid siendo nombrado en 1945 secretario de la dirección central de la Junta Nacional de Acción Católica, aprovechando su sólida formación y larga experiencia que aprovechó para sistematizar algunos manuales al respecto ${ }^{67}$.

Por las características de este artículo, resulta harto difícil detenernos en la concepción que el profesor Sanvisens fraguó de la Pedagogía General, vivificada

65 Sanvisens, Alexandre: Don Tomàs Carreras Artau, patrici gironí, Barcelona, Universitat Ramon Llull-Facultat de Filosofia de Catalunya, 2005.

66 Bonet, Alberto: Un viatge de cara als joves, Barcelona, Imprenta Subirana, I93I.

${ }^{67}$ Bonet, Alberto: Manual de Acción Católica, Madrid, Ediciones Acción Católica, 1962 (2. ${ }^{a}$ ed.). 
ALBERTO BONET Y SU ESTUDIO SOBRE LA CONCIENCIA MORAL DEL NIÑO (I927): A PROPÓSITO DE LOS PRIMEROS TRABAJOS SOBRE LA EDUCACIÓN MORAL ... MONSERRAT PAYÁ SÁNCHEZ Y CONRAD VILANOU TORRANO

por las aportaciones de la cibernética. Con todo, no podemos perder de vista que el profesor Sanvisens -uno de los introductores de la cibernética en España- había publicado, desde la década de los años cincuenta, una serie de artículos científicos que la prensa de la época calificó con el elogioso adjetivo de «luminosos» ${ }^{68}$. Bajo la influencia de la cibernética, cabe señalar que, en diferentes sitios, el profesor Sanvisens dejó constancia de que la educación se asienta sobre cuatro bases o pilares fundamentales: hombre, sociedad, cultura y comunicación. Según este enfoque, la educación se refiere al ser humano (a la persona dotada de conciencia), a la sociedad (a las instancias formales, no formales e informales o cósmicas, esquema ya presente en el universo pedagógico de mosén Bonet), a la cultura (entendida en su totalidad y, por ende, a la simbiosis de las artes, las ciencias y las letras) y a la comunicación (a los medios y a las nuevas tecnologías). Por tanto, se encuentra determinada por estos cuatro factores que hacen que la educación sea lo que es. Pero, por esta misma razón, la educación, recíprocamente, influye sobre la persona, la sociedad, la cultura y la comunicación. De esta manera, se establece un circuito que explica, al mismo tiempo, el sentido del proceso educativo y la estructura constituyente del sistema de la educación. Se trata, pues, de una aproximación sistémico-cibernética al mundo de la educación, que funciona como un sistema abierto a la mejora y optimización, de modo que el todo es mucho más importante que la consideración aislada de cada de una de las partes o elementos. Al fin de cuentas, la visión de conjunto del profesor Sanvisens partía de la fusión de lo biológico y de lo filosófico, idea que había adquirido en sus años de formación junto al profesor Tomás Carreras Artau, de quien asumió su interés por los médicos-filósofos.

En consonancia con todo lo expuesto, el profesor Sanvisens dejó consignado que «el problema de la conciencia es uno de los más interesantes e importantes que pueden ser planteados, dada la trascendencia humana y cultural que, sin duda supone» ${ }^{69}$. Después de analizar los diversos tipos o caracterizaciones de la conciencia (psicofisiológica, psíquica, social, histórica, etc.) se detiene en la conciencia moral que apunta hacia la determinación ética o conductual de la persona. Para el Dr. Sanvisens -que había traducido la Sociología de Jacques Leclercq-70

68 Tомás Cавот, José: «La cibernética en Barcelona (4). De los ingenieros a los filósofos», La Vanguardia, 3225I, I2-02-1970, p. 52. José Tomás Cabot, que había iniciado una serie de artículos sobre "La Cibernética en Barcelona», se refería en un trabajo publicado ese día a los «luminosos escritos del profesor Sanvisens». Después de detallar con precisión sus estudios sobre el tema, interés que se inició en 1956 con la traducción de La Cibernética de G. T. Guilbaud, José Tomás Cabot aconsejaba la conveniencia, a la vista de la dificultad de localizar los escritos del profesor Sanvisens, de que se elaborara un «libro al alcance de todo el mundo». Hubo que esperar todavía unos años para que, a instancias del profesor Antonio J. Colom Cañellas, apareciese la obra del profesor SAnvisens Cibernética de lo bumano (Barcelona, Oikos-Tau, I984), que reúne lo más substancial de su producción cibernética.

69 Sanvisens, Alejandro: «La conciencia en educación», en Pagés Santacana, Anna (comp.): Hombre y educación, Barcelona, PPU, 1989, pp. 266-299 [La cita corresponde a la p. 27I].

70 Leclerce, Jacques: Introducción a la sociología, Barcelona, Instituto de Estudios Sociales de Barcelona, I955. 
ALBERTO BONET Y SU ESTUDIO SOBRE LA CONCIENCIA MORAL DEL NIÑO (I927):

A PROPÓSITO DE LOS PRIMEROS TRABAJOS SOBRE LA EDUCACIÓN MORAL ... MONSERRAT PAYÁ SÁNCHEZ Y CONRAD VILANOU TORRANO

la conciencia moral se relaciona con la conciencia social, entendida por una parte como «una dimensión de la conciencia psicoética en relación con la colectividad -grupo, comunidad, sociedad-y, por otra, muy importante, como una supraconciencia colectiva que tiene, en cierto modo, entidad propia, y que ha llevado incluso a considerar una conciencia nacional o de los pueblos, una conciencia objetiva o trascendente y otras abstracciones» ${ }^{71}$.

Bien mirado, Alejandro Sanvisens se ocupó en diferentes lugares y momentos de la conciencia en educación. Así, por ejemplo, se refirió a la cuestión de la conciencia en la conferencia que con este título - La conciencia en la educaciónpronunció el 26 de marzo de I988, dictada en el Auditorio San Jaime de la Caixa de Barcelona, como clausura al Simposio Internacional de Filosofía de la Educación, que había organizado el profesor Octavio Fullat. Además de publicada en las actas de aquel Simposio se incorporó -como hemos visto- al libro Hombre y educación, coordinado por la profesora Anna Pagés.

De hecho, su interés por el tema venía de tiempo atrás, confiriendo a la conciencia una dimensión cibernética-Dimensión cibernética del problema de la conciencia - tal como manifestó en el Primer Congreso Internacional sobre Ciencia, Conciencia y Estructura del Conocimiento, celebrado en Barcelona, el 28 de junio de i980. Lamentablemente no se ha conservado el texto íntegro de esta conferencia, a pesar de que sí tenemos el resumen que se insertó en el programa de aquel certamen, que reproducimos a continuación:

Dimensión cibernética del problema de la conciencia. La evolución del hombre y la evolución de la conciencia son correlativas. Todo el proceso de desenvolvimiento humano puede interpretarse como un proceso de autognosis y, con ello, un proceso de autodeterminación. Pensar, en el fondo, es descubrirse. Conocer es conocerse. Esto no implica exclusión de la referencia exterior, o sea, del conocimiento de los objetos externos y del mundo; precisamente, el conocimiento de lo demás y de los demás contribuye al conocimiento propio. El pensamiento puede entenderse como una integración. El problema de la conciencia afecta, entre otros planos, al de la comunicación. Desde el punto de vista sistémico y cibernético dicho problema puede inscribirse en las cuestiones generales de los procesos informativos y de control, incluyendo el tema central de la optimización. Pero para situar debidamente este problema, desde una perspectiva cibernética, deben considerarse los aspectos adaptativo y proyectivo de la optimización y, por ende, de la evolución humana. No basta atender tan sólo a la retroacción, pues difícilmente podríamos interpretar los procesos creativos y verdaderamente evolutivos del desarrollo humano. Entre estos se integran la espontaneidad y la libertad. Atendiendo al tratamiento de dicho desarrollo, que afecta al quehacer pedagógico, pueden examinarse varias consecuencias. En primer lugar, la educación -sistema abierto y evolutivo- debe implicar, como constitutivo importante, un camino para encontrarnos a nosotros mismos. En cierta manera, un encuentro. Una educación meramente externalista deja de ser una educación propiamente humana. Pero no debe

${ }^{71}$ Sanvisens, Alejandro: «La conciencia en educación», en Pagés Santacana, Anna (comp.): Hombre y educación, op. cit., p. 279. 
ALBERTO BONET Y SU ESTUDIO SOBRE LA CONCIENCIA MORAL DEL NIÑO (I927): A PROPÓSITO DE LOS PRIMEROS TRABAJOS SOBRE LA EDUCACIÓN MORAL ... MONSERRAT PAYÁ SÁNCHEZ Y CONRAD VILANOU TORRANO

caerse en un subjetivismo cerrado, sino partir del hombre, de la conciencia y de la educación como sistemas abiertos. Interconexionados con la sociedad y con la cultura. En otro término, la educación tenderá a ser proyectiva y descubrir caminos de perfeccionamiento y superación. Conviene advertir que la interpretación cibernética de la conciencia y del proceso consciente no es exclusiva ni se reduce a un mecanismo extrapersonal o antihumanista; al contrario, trata de situarse en un plano de consideración humana, integrando las aportaciones del análisis de la vida interior y del análisis de la naturaleza, en sentido dinámico. También la «conciencia colectiva» puede ser interpretada en sentido sistémico y cibernético, como un proceso de información y de control adaptativo y proyectivo. Un estudio de la inteligencia creativa debe incluir el aspecto individual y el colectivo o, en alguna forma, social, como dos dimensiones de un proceso optimizante de la conciencia personal.

Nuestro maestro también puso en relación la conciencia con la esfera de la información y el control, destacando su papel -el de la conciencia- como fundamento de la optimización superior. Al fin de cuentas, el hombre posee el mejor feed-back que existe al regular su propia acción. En realidad, se dan diferentes tipos de optimización: adaptativa, basada en la retroacción delfeed-back; proyectiva, fundamentada en el control anticipatorio o feed-before; introyectiva, entendida como el hecho de conciencia que permite al ser humano la autorregulación de su conducta. En aras de la brevedad hemos de soslayar diversos aspectos que Sanvisens aplica a la conciencia que pueden favorecer y dar como resultado una comprensión subjetiva, un sentido de la objetividad, un personalismo formativo, un autodominio, una capacidad de relación, de trato, de promoción de la capacidad crítica y de la capacidad creativa.

En resumidas cuentas, el doctor Sanvisens profundizó en la conciencia para descubrir las leyes de la naturaleza humana de acuerdo con los postulados de la filosofía del sentido común de Francisco J. Llorens Barba, quien afirmaba -como hemos visto- que la existencia de la ley moral es un hecho primigenio de la conciencia humana. No extraña, pues, que el doctor Sanvisens encontrase en la filosofía del sentido común una base para desarrollar su pedagogía de la conciencia, ya que el mismo Llorens en la lección primera del libro primero («Psicología empírica») de sus Lecciones de Filosofía había dejado constancia de la necesidad de atender tanto a la razón teorética que regula el conocimiento como a la razón práctica que se ocupa de la praxis moral:

La Filosofía del Sentido Común, no solamente entiende poder decir algo de la existencia que está más allá de nuestra observación inmediata en virtud del pensamiento especulativo, sino también en virtud del pensamiento práctico. Mientras la Metafísica abstractiva no admite sino lo que en realidad podemos conocer de esa existencia trascendental, al modo que la Física, por ejemplo, no admite sino lo que podemos conocer por medio de los sentidos, la Filosofía del Sentido Común no mutila así al hombre, sino que lo toma en su integridad (nos referimos al hombre interior, pues no hablamos del hombre físico); toma repetimos, en su totalidad al hombre, al alma humana, buscando en su esfera cognoscitiva qué 
ALBERTO BONET Y SU ESTUDIO SOBRE LA CONCIENCIA MORAL DEL NIÑO (I927): A PROPÓSITO DE LOS PRIMEROS TRABAJOS SOBRE LA EDUCACIÓN MORAL ... MONSERRAT PAYÁ SÁNCHEZ Y CONRAD VILANOU TORRANO

existencias corresponden a sus actos, como en su esfera volitiva cuáles corresponden a sus $\operatorname{actos}^{72}$.

Además, podemos añadir que Alejandro Sanvisens -en una actitud que recuerda la posición de su maestro Tomás Carreras Artau- se adscribía a una ética socrática basada en la introspección, esto es, en la interiorización hacia la propia conciencia, si bien se encuentra influida por el entorno social donde se desarrolla la persona que siempre permanece abierta a la optimización. Tanto es así que la historia del ser humano es la historia del descubrimiento y la caracterización de su conciencia, con las consecuencias resultantes de su libertad y responsabilidad.

Ante una sociedad en crisis, el profesor Sanvisens no sólo reclamaba el papel de la conciencia, sino algo más: la configuración de la figura del pedagogo -denostado y discutido ya entonces- como un guía y regulador de la conducta de los jóvenes. Cabalmente, abogaba por la substitución de la Ética -alternativa a la Religión- que se impartía en educación secundaria por una nueva disciplina de Conducta. «Podría atender a los aspectos individuales y sociales, comunitarios, en sentido integrador y orientador, respetando la libertad de las personas $»^{73}$.

Por consiguiente, el profesor Sanvisens reclamaba para la pedagogía una especie de educación de la conciencia, educación de la personalidad, educación de la conducta, esto es, una educación moral que «debería abarcar o, mejor, integrar el tipo de formación que propugnamos». Así concluía el profesor Sanvisens que reivindicaba para el pedagogo su talante conductivo, orientador y educador, es decir, pedagógico en el sentido radical del término lo cual implicaba una dimensión de guía y acompañamiento, sin perder de vista el aspecto normativo en consonancia con los planteamientos de Herbart. A la larga, y sobre la base de esta tradición filosófica y pedagógica que destaca la pedagogía de la conciencia y, por ende, la conciencia moral del niño ya estudiada de manera pionera por Alberto Bonet en I927, apareció en I988 el GREM (Grup de Recerca en Educació Moral) en el marco de la Universidad de Barcelona, que ha dinamizado diversos trabajos y líneas en el ámbito de la educación en valores. Pero ésta es otra historia que dejaremos, con el beneplácito del público lector, para otra ocasión.

72 Llorens y Barba, Francisco Javier: Lecciones de filosofía. Explicadas en la Universidad Literaria de Barcelona durante los cursos de 1864-65 y 1867-68, taquigrafiadas por José Balari y Jovany, op. cit., vol. I, «Psicología empírica, Lección primera», pp. II-I2.

73 Sanvisens, Alejandro: «La conciencia en educación», en Pagés Santacana, Anna (comp.): Hombre y educación, op. cit., p. 298. 